Article

\title{
A methodology for assessing the implementation potential for retrofitted and multifunctional urban green infrastructure in public areas
}

\author{
Tanja Fluhrer ${ }^{1}$ and Jochen Hack ${ }^{2, *}$ \\ 1 TechnicalUniversity of Darmstadt, De partment of Civil and Environmental Enginee ring; contact@geo.tu- \\ darmstadt.de \\ 2 Technical University of Darmstadt, Institute of Applied Geosciences, Section of Ecologic al Enginee ring, \\ Research Group SEE-URBAN-WATER; hack@geo.tu-darmstadt.de \\ * Corre spondence: hack@geo.tu-darmstadt.de (J.H.)
}

\begin{abstract}
Green Infrastructures (GI) are considered key to reconcile ecological and social benefits by providing multiple functions. The concept is increasingly promoted and guidelines for its implementation have been developed in many countries and regions of the Western Hemisphere. However, for other parts of the world, especially for countries with less developed infrastructures, promotion, guidance for decision-making and manuals for GI are often lacking. But the state of infrastructure development and often unplanned character of settlem ents in the Global South differ and result in specific constraints as well as demands to GI that need to be addressed explicitly. This study presents a methodological approach to explicitly address the specific conditions and physical limitations to GI development in urban areas of the Global South. A four step methodology was developed to assess the implementation potential for retrofitted and multifunctional urban green infrastructure in public areas. An initial site analysis (1) and the definition of design criteria as well as general strategies (2) to achieve the different dimensions of multi-functionality are the basis to derive spatial typologies (3) for GI elements and finally the spatial suitability assessment for potential placements (4). An application of the methodology to a study area in the metropolitan region of San José, Costa Rica, shows exemplarily that the potential to improve the hydrological conditions (up to $34 \%$ of surface runoff reduction), ecological conditions (increase of green space by $2,2 \%$, creation of $1500 \mathrm{~m}$ length of roadside greenery and tw o new habitat types), and social conditions ( $2.200 \mathrm{~m}$ of road type upgrading) of multi-functionality of the site through Green Infrastructures. These assessment results of different multi-functionality dimension can serve as a guidance for GI promotion and implementation in urban areas of the Global South.
\end{abstract}

Keywords: Green Infrastructure; urban; multi-functionality; retrofitting; sustainability; neighborhood level; Costa Rica

\section{Introduction}

Nature-based Solutions (NbS), measures adapting or based on natural processes addressing societal challenges, have been identified as a promising approach to deal with socio-ecological problems [1]. Recently, NbS are being considered specifically for urban contexts. In Europe, for instance, the European Commission is funding with the NATURVATION (NATure-based URban innovation) a 4year project (2017-2020) involving 14 institutions across Europe to investigate the potential NbS for responding to urban sustainability challenges [2]. In the USA, NbS in urban contexts are referred to as Green Infrastructure which are country-wide promoted through a special program of the United States Environmental Protection Agency (EPA) based on the Clean Water Act [3]. As a result, several policy and technical guidelines to promote an implement Green Infrastructures have been produced for the US. A related concept with similar guidance has been established in Australia with Water Sensitive Urban Design (WSUD). Federal, State and Territory governments of Australia agreed upon the National Water Initiative (NWI) in 2004 and 2006 which intends to "Create Water Sensitive Australian Cities" and encourages adoption of WSUD approaches [4]. These developments demonstrate that planning and 
implementing guidelines, at least in the USA, Australia and the United Kingdom (Sustainable Urban Drainage Systems), for NbS in urban context exist and that these approaches are being promoted for implementation. However, applications often are new urban developments or adaptations and modifications of existing urban drainage structures and green spaces.

In the Global South, governments and public authorities have not yet adopted NbS. Urban development in many parts of the Global South has happened informally or unplanned resulting in urban areas without urban drainage and wastewater treatment systems together with a lack of public or private green spaces [5]. This has led to significant environmental damages, e.g. biodiversity loss due to habitat loss and environmental contamination [6], as well as to few recreational or healthy areas for social well-being [7]. The potential multi-functionality of Urban Green Infrastructures (UGI), which has been proven for instance in the US [8] and in different European cities (Berlin, Edinburgh, and Aarhus) [9], to address these deficits also in urban areas of the Global South is highly probable. But due to the lack or deficiency of public infrastructure and often unplanned character of settlements, the conditions differ from those of cities in the Western Hemisphere. Studies that explicitly address the specific conditions and physical limitations to UGI development as well as the potential for multifunctional implementation are generally lacking. Considering multi-functionality in the development of UGI may facilitate a comprehensive upgrading of residential areas.

We address this research gap with our study by proposing a methodology that provides guidance for the placement, geometries and spatial distribution of multifunctional UGI elements on a neighborhood scale for a tropical country of the Global South. The methodology builds on insights from existing UGI design guidelines and consists of four steps: (1) Analysis of the site, (2) Definition of design criteria and implementation strategies, (3) Development of spatial ty pologies, and (4) Spatial suitability assessment of GI elements. The multi-functionality of UGI considers three dimensions (a hydrological, an ecological and a social dimension) and is integrated in the definition of design criteria and implementation strategies of step (2) of the methodology.

The methodology is exemplary applied to a small urban study area within the metropolitan region of San José in Costa Rica. The analysis is based on a detailed on-site data collection, as well as content from international literature and studies on the topic of multifunctional UGI and their design. The objective is to investigate the opportunities of implementing different UGI elements with respect to their design due to spatial placement, distribution and geometries in the exemplary study area. Thereby, the practical application of our methodology is demonstrated.

Our results show in detail the explicit spatial placement potential for different kinds of retrofitted UGI elements of suitablegeometries within a dense urban fabric and the degree of multi-functionality that could be achieved in each of the considered dimensions. This allows for the implementation of retrofitted UGI adapted to the specific conditions and constraints of urban areas in the Global South, such as - constraints due to vehicle traffic and drivew ays, predominant road designs, as w ell as presence and spatial distribution of existing green features within the urban matrix. We conclude that the proposed methodology provides a suitable basis for the development of placement strategies (geometries of prototy pes, spatial distribution at the neighborhood scale) for local planners to achieve a high degree of multi-functionality and to promote UGI elements as valuable integral components of urban planning.

\section{Materials and Methods}

Multi-functionality is a principal characteristic of GI [8-10]. It means that GI - or more generally, green space, - provides a variety of functions, for example ecological, social and economic [9]. Especially in the application of UGI, their hydrological function in the context of storm water management plays an extraordinary role [11]. A decisive factor for the achievement of different functionalities is above all the specific design (geometries and spatial distribution) and placement, i.e. embedding, of green infrastructure elements in space. In an urban, retrofitting context, space is a usually very limited and predefined by competing single-purpose functions, e.g. vehicle traffic or housing [12]. In the following, we propose a general methodology to affectively improve multi-functionality in an urban residential retrofitting setting through a specific placement strategy. 
The achievement of a high degree of multi-functionality is intended through a coherent placement and spatial distribution strategy that facilitates the creation of networks and increases connectivity by interlinking existing green spaces functionally and physically with newly placed UGI elements on a neighborhood scale. Thereby, an integration and combination of existing green spaces and UGI elements with other urban infrastructures such as transport infrastructure, drainage systems and other built structures is pursued. The methodology is not intended to provide a single right solution, but as a feasible way to context-specifically consider particular limitations or constraints of a site to multifunctional UGI implementation and to best exploit the landscape potential based on empirically revealed conditions.

The specific assembling, properties and spatial distribution such as the areas occupied by houses, sidewalks, streets, green and other public or private spaces as well as the use of these spaces reveal specific constraints and opportunities for multifunctional UGI. Since several UGI elements are available for implementation, but not all techniques are suitable for all potential sites, it is important to define constraints and opportunities in an early stage of the design process to select the most suitable elements later [13]. Therefore, the spatial configuration of these site features is analyzed first in a methodological step (1) as the basis for multifunctional UGI implementation. The analyzed features represent characteristics of the site, referring to the landscape, particular urban elements and further characteristics (topography, spatial distribution of property situations, land uses, green spaces and drainage system). In the next methodological step (2), design criteria and placement strategies to achieve a high degree of multi-functionality have to be defined. Adapted to the general conditions and the potential of the site, they allow to state practical hypothesis, priorities and possible decisions for the design process. For prioritizing and selecting suitable design criteria, the previous analysis of the site (Step 1) is supportive. Due to the multifunctional character of UGI many different design criteria can be set besides storm water control, for examplebiodiversity enhancement, urban heat island reduction, air quality improvement, social cohesion, recreation and/or education. Strategies specify the defined design criteria and concretize their implementation. By defining spatial typologies for different UGIs based on the site analysis (1) in a third step (3), a portfolio of suitablelocations with in the neighborhood can be elaborated. Depending on, for instance, dominating road netw ork characteristics, their dimensions and traffic volumes, various scenarios and priorities can be set to define the best suitable locations of implementation within the road system. Or regarding open spaces, dependent on their characteristics, suitable UGI types can be defined. Depending on which information is available, further criteria can be added. A detailed investigation of possible UGI elements should be carried out in advance in order to understand functions of different elements and to select the most suitable ones. Limitations for placement options and geometry are given by the features of the site (defined in Step 1), the spatial typologies (defined in Step 3), and general recommended design parameters of individual UGI elements (e.g. the maximum attached drainage area). For instance, minimum space requirements of specific elements can be determined depending on the desired design functionality target respectively design storm events for hydrological performance. Based on this, design proposals can be developed with specific suggestions for placement, dimensions, and technical configurations in a last step (4).

See Figure 1 for an illustration of the four step methodology.

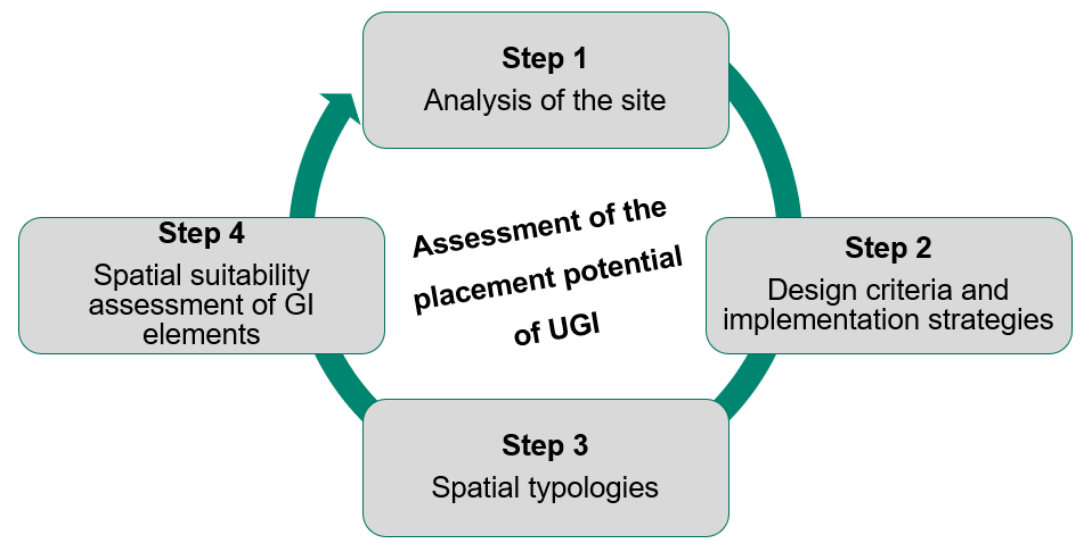

Figure 1: Methodological steps to assess the placement potential of multifunctional Urban Green Infrastructure 
To illustrate the proposed methodology in more detail, its application is described in the context of our case study example. A description of how each methodological step is carried out, what kind of information/data is used, and what are the specific results is given.

\subsection{Step 1 - Analysis of the site (Study area)}

The study area represents a typical highly-urbanized residential area located within the Great Metropolitan Area around $13 \mathrm{~km}$ northwest of the capital San José in Costa Rica. Its area of 33 ha with a population of 2.510 is mainly narrowly built with well develop streets for vehicle use and it is characterized by a steady population growth and only few small green and recreational areas. This results in a severe limitation in the availability of space for UGI implementation. Furthermore, the area represents a hydrologically closed drainage area within the urban watershed “Quebrada Seca - Río Burío" (see Figure 2).

As part of the first methodological step (Analysis of the site), spatial information was gathered mostly through field work (georeferenced recording and tracking of site features) through the Research Group SEE-URBAN-WATER ${ }^{1}$ during April to August 2019, while additional information (cadastral map, street netw ork, property situation, topography) w as provided by the local municipality of Flores. Additionally, drone videos were used to retrieve aerial information. The data was then digitalized in GIS for further analysis. The kind of information were gathered and the specific intermediate results as basis for the definition of design criteria and implementation/placement strategies (methodological step 2 ) is explained in the following.

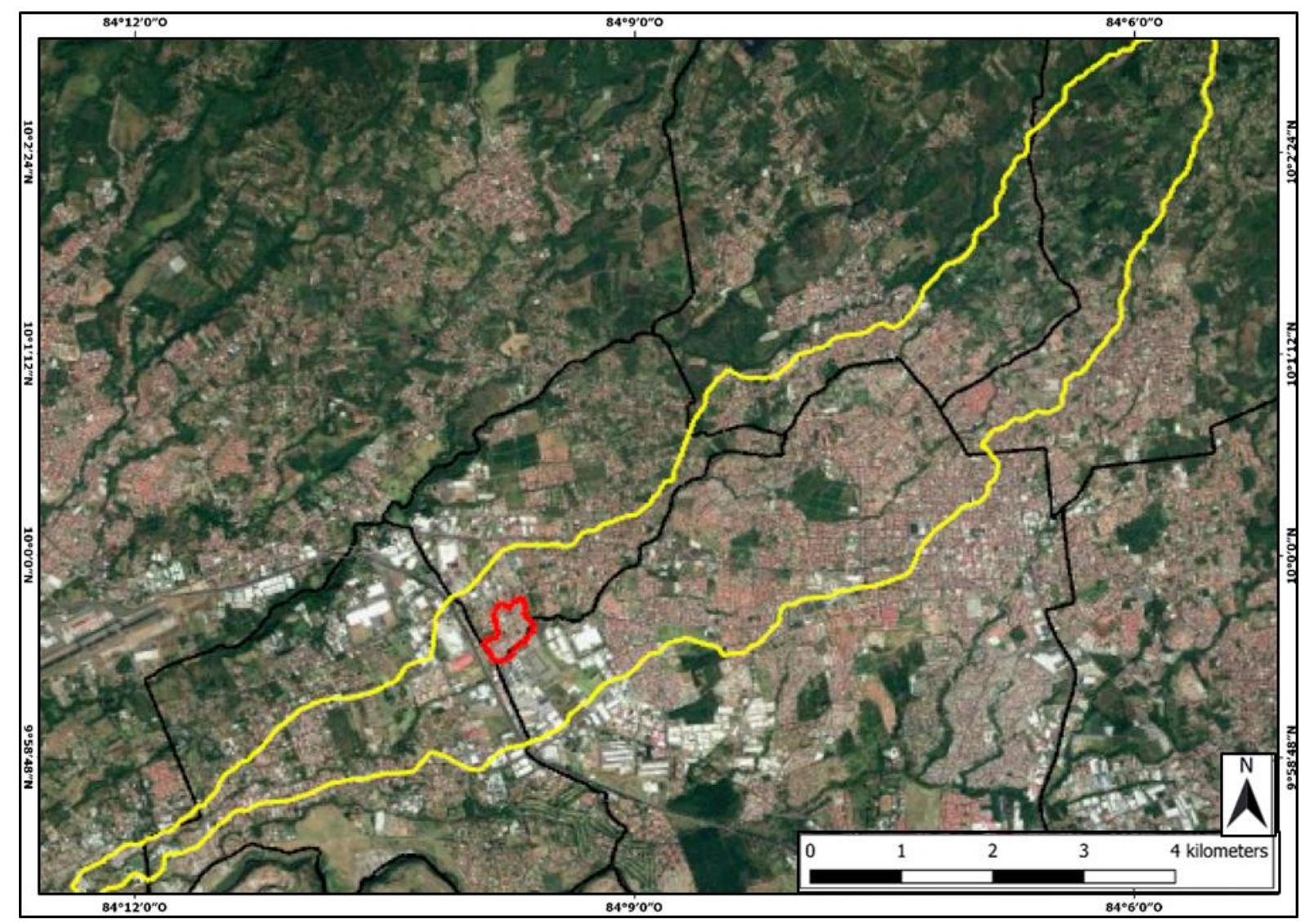

Figure 2: Map of the larger Quebrada Seca - Burío Catchment (yellow) and the study area (red) in the Metropolitan Area of San José, Costa Rica. Black lines represent municipal boundaries. (Source of background satellite image: Google Earth)

\footnotetext{
${ }^{1}$ www.tu-darmstadt.de/see-urban-water
} 


\subsubsection{Existing green network and social accessibility}

The study area is mostly residential, with around $60 \%$ of the area cover by houses. The few existing green spaces, mainly located along the river, are categorized in recreational areas (playgrounds and sports facilities), vacant land (in public hand), undeveloped properties (in privatehand), riparian land and other unsealed areas. In streets a sparse netw ork of green verges and roadside greenery exists. We consider the accessibility of recreational areas with regard to proximity (distance and time to reach a recreational green space within a neighborhood) and aerial extend. International standards vary here in their suggestions: The WHO suggests at least one 2 ha large green area no more than $300 \mathrm{~m}$ linear distance defined as 5 minutes' walk from home [14]. Whereas the "European Common Indicator" only suggests a minimum 0,5 ha public green area within $300 \mathrm{~m}$ [15].

While in the study area the three largest recreational areas can be reached almost by all residents within $300 \mathrm{~m}$ linear distance (see Figure 3), access is mostly limited to highly trafficked roads and with many detours, due to many dead-end roads. Hence, the walking distance exceeds 5 minutes from most points. Also, the largest recreational green space of $2.838 \mathrm{~m}^{2}$ does not meet the suggested 0,5 ha. Per habitant green space recommendations indicate $5 \mathrm{~m}^{2}$ per habitant [15]. In this study's case, only 10.960 $\mathrm{m}^{2}$ of public recreational green space are available per habitant, $12.550 \mathrm{~m}^{2} \mathrm{w}$ ould be needed to meet the recommendation. Thus, the dispersed, too small and hardly accessible public green spaces of study area are a clear deficit in social functioning, but also in ecological and hydrological functioning.

Figure 3 illustrates the spatial distribution in quantity and quality of existing green and unbuilt spaces as well as their accessibility.

\section{Green network}

- Roadside greenery

\begin{tabular}{l}
\hline \multicolumn{2}{c}{ Green verge } \\
\hline \\
\hline
\end{tabular}

- Endpoint dead-end road

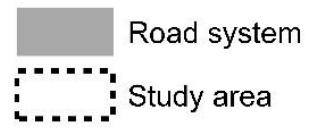

River "Quebrada Seca"

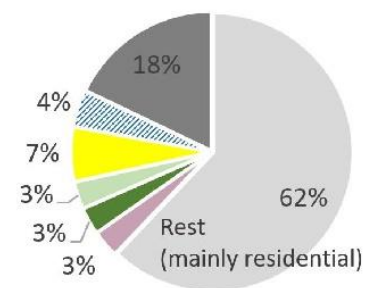

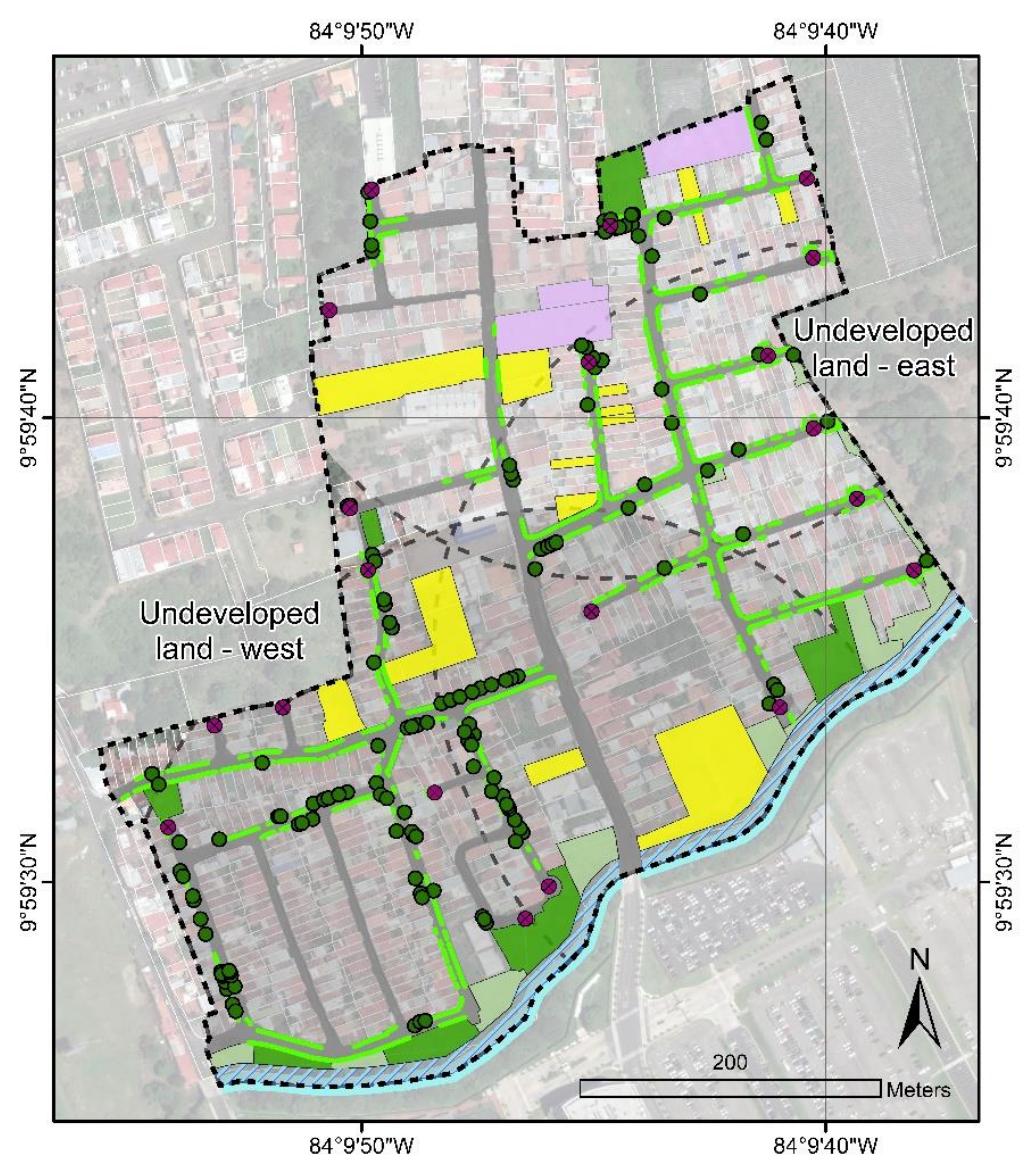

$84^{\circ} 9^{\prime} 50^{\prime \prime} \mathrm{W}$

Figure 3: Map of the study a re a illustrating the existing ne twork of green elements, land use distribution and $300 \mathrm{~m}$ distance limits for recreational areas (Source of background satellite image: Google Earth).

\subsubsection{Existing drainage system}

Domestic greywater, together with storm water from sealed surfaces and roofs, is routed through open gutters in the streets into inlets to the sewer system. From there the runoff is directly drained without any treatment to the next waterbody. This kind of storm and wastewater handling is very 
typical for the entire Greater Metropolitan Area and for other urban areas in tropical countries. It promotes a fast conveyance of high amounts of strom water and untreated grey water to natural water bodies without consideration of other ecological, hydrological or social functions of the drainage areas. Based on the 10 outfalls to the river, the study area can further be divided into seven sub-basins varying in size from 0,7 to 9,6 ha. Figure 4 illustrates the spatial delimitation of individual drainage netw orks in size, discharge directions, number of connected units, and outfalls to the river.

\section{Drainage system}

\begin{aligned} & \hline Sub-basin \\ & \hline Outfall river/study area \\ &$\square \quad$ Sewer inlet \\ &$\bullet \quad$ "Drainage divide point" \\ & -..-- Drainage path \\ & Road system \\ & River "Quebrada Seca" \end{aligned}

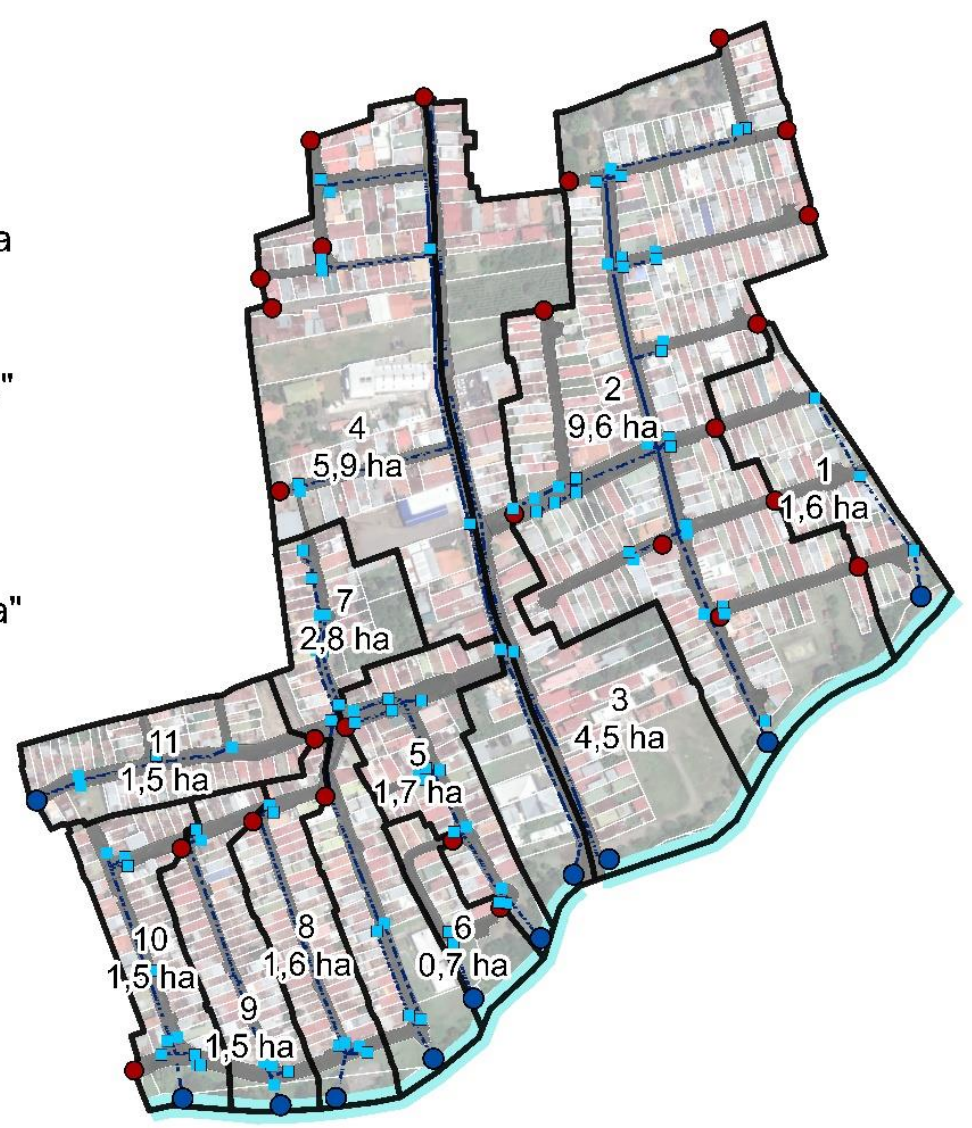

Figure 4: Map of the study a rea's storm water drainage system, including sub-basin, drainage paths and divide points (Source of background satellite image: Google Earth).

\subsubsection{Road typology and hierarchy}

The area has a well-developed road network focused on motorized traffic. The uniform profile consists typically of two road lanes, sidewalks on both sides, frequently interrupted by driveways entering the properties, often green verges and gutter for the open discharge of runoff. Central median, parking and bicycle lanes do not exist. Speed humps and on-street parking can be found as the only traffic flow regulating elements. Within the study area, the road components ranging in their dimensions. Based on representative cross section measurements at nine different locations, the roads are classified into four hierarchical types: access roads, local roads, residential roads and small residential roads. According to this classification, most streets are residential roads as dead-end roads. Based on a traffic counting and field observations, roads are further classified according to their traffic volume relative to the traffic in the entire study area. Hence, very high traffic volume is estimated for the only direct through road. High traffic volumes ( $>250$ cars per hour counted) are expected on roads connecting to the free trade zone and medium traffic volume for further connecting roads. Low traffic volume can be expected for all dead-end roads and small residential roads. Resulting from the combination of road hierarchy and traffic volume, different road types (1-5) are defined. Figure 5 illustrates the spatial distribution of road types (categories) based on road hierarchies and traffic volumes. The road type is directly linked to the available space for and the specific type of UGI as well as possible functions. Due to the topography, all roads with North-South direction have a steep slope draining to the river in the South. 

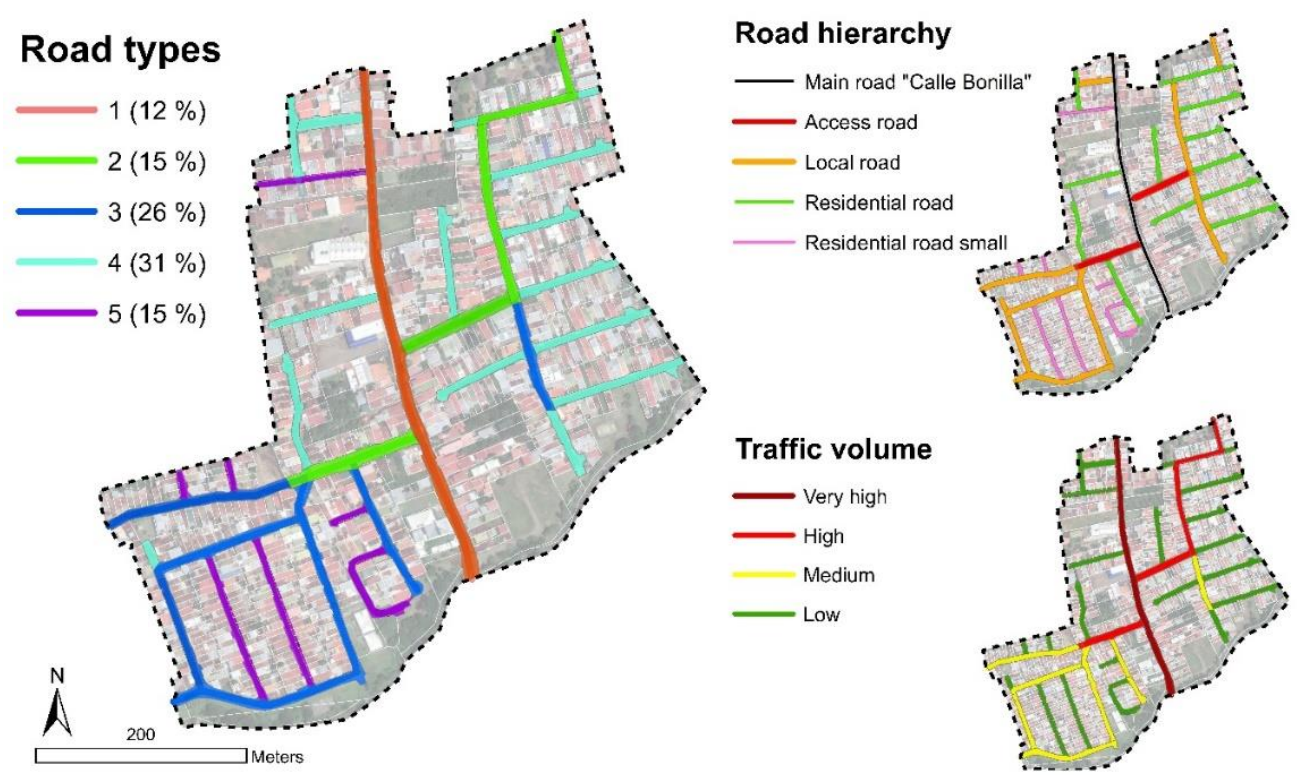

Figure 5: Spatial distribution of road types (1-5), road hierarchies and traffic volumes within the study area (Source of background satellite image: Google Earth).

\subsection{Step 2 - Design criteria and placement strategies}

Given an urban context and the need to foster implementation of UGI strategies in less developed countries with lacking basic infrastructures and green spaces, we focus in this study on three dimensions of multi-functionality: a hydrological, an ecological and a social dimension. In order to develop a methodology easily applicable in practice, we prioritize the specific functionality to be enhance in the three dimensions using respective design criteria and strategies for dimension-related improvements (see Figure 6). In our methodological understanding, criteria define "what" the UGI placement and design should achieve, the strategies describe "how" or "by which means". A vision unites the strategies and can be formulated as: "Linking green spaces through multifunct ional Urban Green Infrastructures in roads and open spaces to create an interconnected netw ork that reduces surface runoff, provides opportunities for social activities, increases safe accessibility within the neighborhood and enhances thebiodiversity of the site."

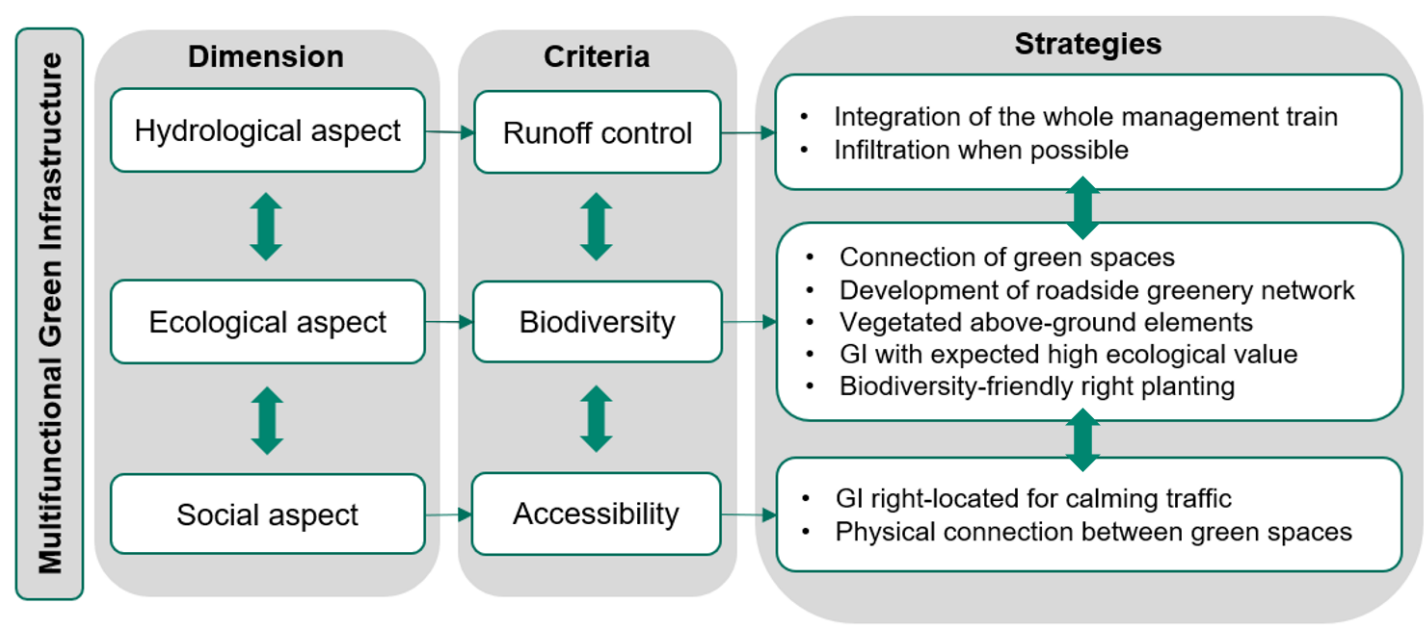

Figure 6: Dimensions, criteria and strategies for MultifunctionalGreen Infrastructure used in this study.

In our case study application, the prioritized criterion for the hydrological dimension is runoff control. It aims to mimic the natural water cycle by reducing storm w ater generation through infiltration and retention to increase evapotranspiration. A side effect of achieving these aims is a minimization of water pollution through contaminated urban runoff discharging to urban streams. A preliminary quantitative runoff control focus is chosen because of the significant problems of urban flooding 
encountered in densely urbanized tropical regions [16] and the specific capacity of UGI in addressing them [17]. The strategy to accomplish the criterion of runoff control is to increase infiltration of precipitation and to integrate the whole management train of UGI in the urban landscape. To evaluate the degree of achievement of this hydrological multi-functionality dimension (criteria runoff control), design proposals are assessed regarding the [0-100] \% increase of runoff storage capacity and the number of elements of different parts of the management train (source control, convey ance, end-control; [0-3]) considered.

Within the ecological dimension, the prioritized criterion is biodiversity. The implementation of UGI elements should increase biodiversity through an increase in connectivity and upgrading the ecological value of green spaces. It is assumed that connecting neighboring habitats and by creating larger ecological networks through the placement of ecologically functioning UGIs of additional ecological value, can potentially increase and strengthen biodiversity [18]. A particular opportunity to increase the degree of connectivity of higher ecological value present urban streams with remaining natural conditions (e.g. vegetated river banks, natural river bed and course) $[19,20]$. The ecological multi-functional dimension (criteria biodiversity enhancement) of UGI design proposals is evaluat ed regarding $[0-100] \%$ increase of green space, $[\mathrm{m}]$ length of roadside greenery created, $\left[\mathrm{m}^{2}\right]$ area of vegetated above ground elements created, and $\left[\mathrm{m}^{2}\right]$ of new habitat types created.

Accessibility is in our study the prioritized criterion for the social functionality dimension. It is related to the placement and design of UGI with the aim to calm traffic for better and safer walkability as well to increase the physical connection to green spaces for recreation. The purpose is to encourage active travel, outdoor activities, and recreation within a neighborhood [21]. The criterion of accessibility $\mathrm{w}$ as evaluated based on $[\mathrm{m}]$ length increase of roads with improvement of road category.

The prioritization in multi-functionality in our case study example is guided by hydrological performance, but this has not necessarily to be the case in other applications of the methodology.

\subsection{Step 3 - Spatial typologies}

Target of the next step is a portfolio of suitable public locations within theneighborhood. Defined spatial typologies help to limit possible placements of GI elements within the site. Depending on the defined road typologies in Step 1 various scenarios and priorities can be set in order to define the best suitable locations of implementation within the existing road system. For each road ty pe preferable and second-ranked location as road components for GI implementation are set. Primarily, GI elements are to be integrated where no main functions are affected and enough space is available to prevent conflicts. The main road of the neighborhood is not to be restricted any further, due to tight space conditions and the highest traffic volume (see road ty pe 1). In further roads with high volume of traffic, the aim is not to establish UGI in the road lanes. Preferred road components used for implementing GI elements are gutter and green verges (see road type 2 and 3). But if the dimension and the traffic volume allows it, implementation of GI elements in the road lanes is desirable, offering a pedestrian-friendly design (see road type 4 and 5). An overview of preferential location of UGI for different road types is presented in Table 1 and Figure 7.

Table 1: Definition of road types based on traffic volume and hierarchical order, re lative percentage of total road network and preferred location as well as second-ranked location for UGI.

\begin{tabular}{|c|c|c|c|c|c|}
\hline Road hierarchy & $\begin{array}{l}\text { Traffic } \\
\text { volume }\end{array}$ & $\begin{array}{l}\text { Defined } \\
\text { road type }\end{array}$ & $\begin{array}{l}\text { Percentage of total } \\
\text { road network }\end{array}$ & Preferred location & $\begin{array}{l}\text { Second-ranked } \\
\text { location }\end{array}$ \\
\hline Main road & Very high & 1 & $13 \%$ & - & - \\
\hline Access road & High & \multirow{3}{*}{2} & \multirow{3}{*}{$15 \%$} & \multirow{3}{*}{ Green verge, gutter } & \multirow{3}{*}{ 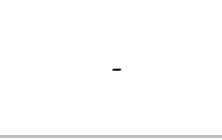 } \\
\hline Local road & High & & & & \\
\hline Residential road & High & & & & \\
\hline Local road & Medium & \multirow{2}{*}{3} & \multirow{2}{*}{$26 \%$} & \multirow{2}{*}{ Green verge, gutter } & \multirow{2}{*}{ Roadlane } \\
\hline Residential road & Medium & & & & \\
\hline Local road & Low & \multirow{2}{*}{4} & \multirow{2}{*}{$31 \%$} & Roadlane, & \multirow{2}{*}{ Sidewalk } \\
\hline Residential road & Low & & & green verge, gutter & \\
\hline Res. road small & Low & 5 & $15 \%$ & Road lane, gutter & Sidewalk \\
\hline
\end{tabular}




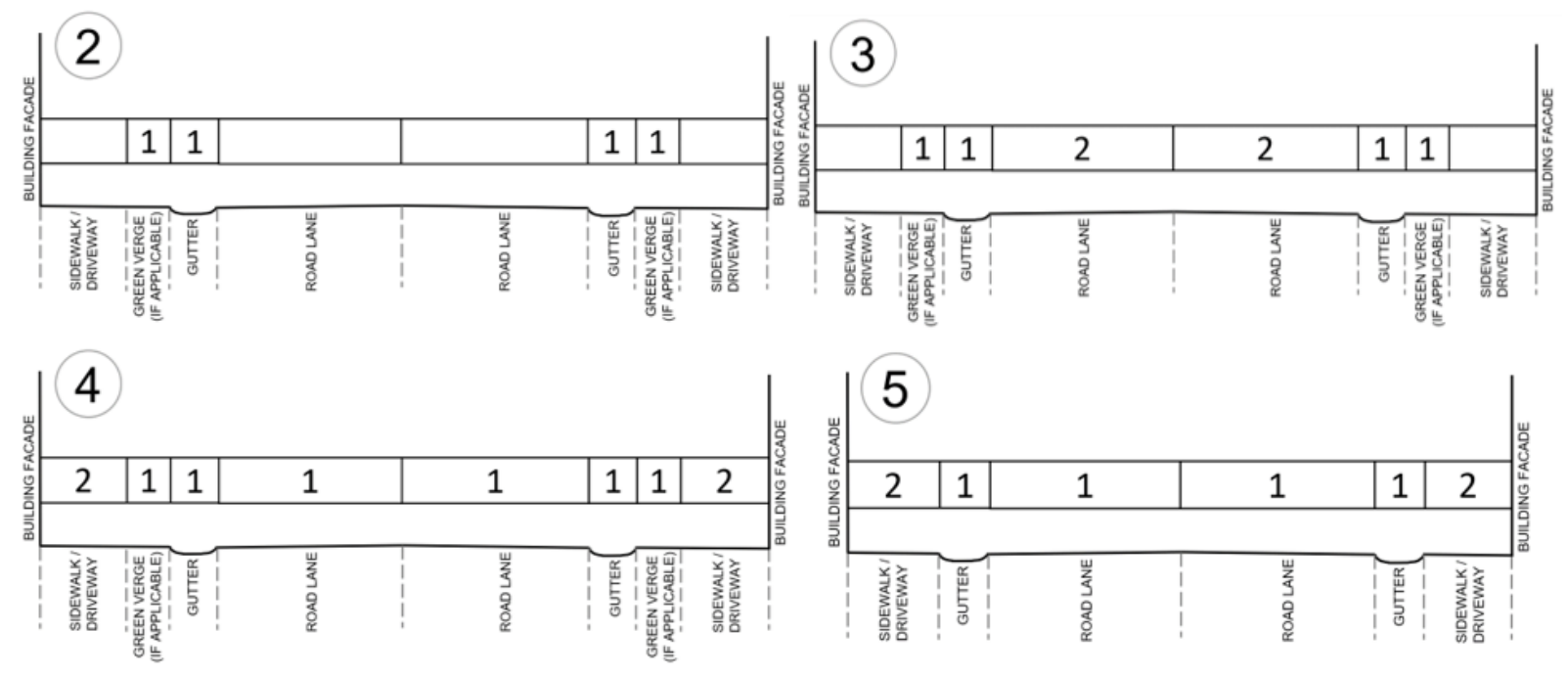

Figure 7: Cross sections of road types 2-5 with indication of pre ferred and second-ranked location of UGI elements

Regarding the implementation of UGI in open spaces, areas of public green space are suitable: Recreational areas, vacant land, and riparian land. Suitable UGI elements for each type of open space can be defined depending on their characteristics. According to this, recreational areas are best suitable for UGI's allowing multi-use. Within the riparian land, elements connecting with the blue netw ork are preferable. Vacant land poses no special requirements. Table 2 shows which characteristic of UGI is appropriate depending on the type of open space.

Table 2: Area of different types of open space in the study area and respective preferred UGI characteristics.

\begin{tabular}{|c|c|c|}
\hline Type of open space & Area $\left.\mathbf{( m}^{\mathbf{2}}\right)$ & Preferred UGI characteristic \\
\hline Recreational area & 10.960 & UGI elements allowing multi-use \\
\hline Vacant land & 8.770 & Imposes no special requirements on elements \\
\hline Riparian land & 11.790 & Elements suitable for connecting with blue network \\
\hline
\end{tabular}

Together with the usable existing road system in total around $24 \%$ of the study area are considered to be suitable for UGI placement (see Figure 8).

\section{Suitable areas for UGI placement}

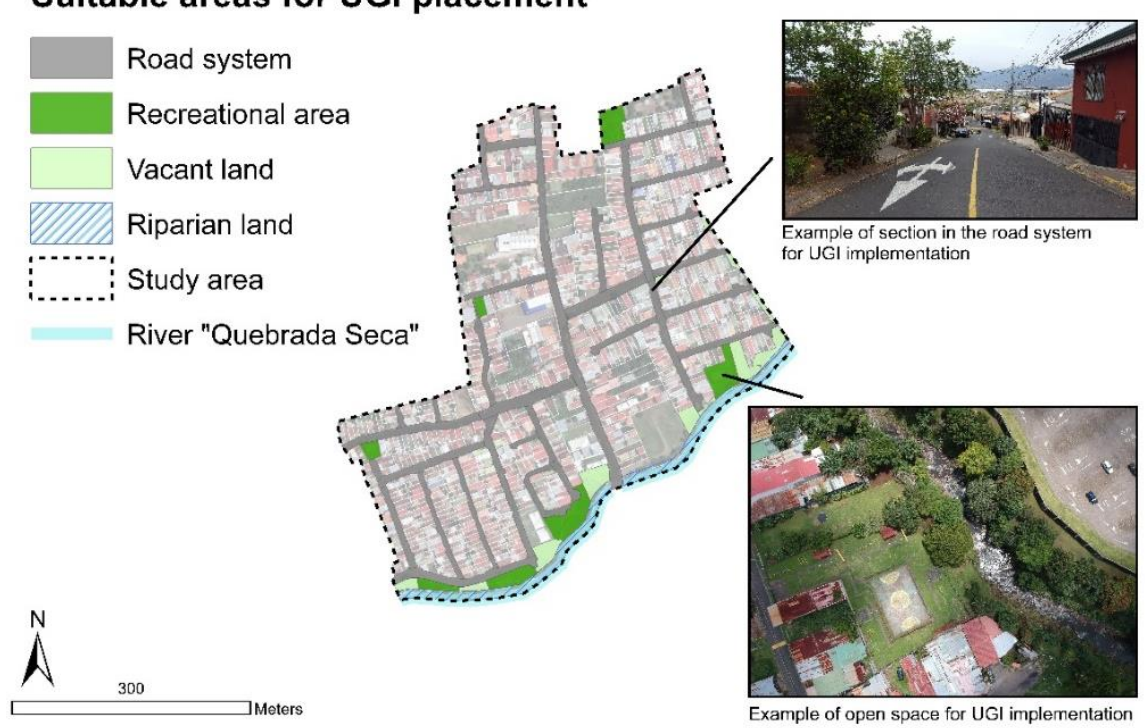

Figure 8: Distribution of suitable a reas for UGI placement in the study area (Source of images: Dennis Jöckel) 
Depending on which information is available, further criteria, e.g. soil conditions, free spaces on properties and roof types, can be added.

\subsection{Step 4 - Spatial suitability assessment of UGI elements}

UGI elements can be categorized in many different ways, among others with respect to their main functions, ecosystem services, components, or scale of application [22,23]. For implementing the most suitable types of UGI elements creating a diverse network across a neighborhood it is necessary to understand the many, often intertwined, functions of UGI elements. There are many features providing important hydrologic functions to control the frequency of runoff, flow rates and volumes of runoff. Therefore, UGI elements for source-control are located more upstream, whereas elements for surface runoff retention have often end-control positions and are located more downstream in the so-called management train [24].

Based on a review of 12 design guidelines [24-35] of 5 countries (United Kingdom, USA, Canada, Australia, and Singapore), common UGI elements implementablein public space in the study area are selected and categorized in Table 3 according to their hydrologic functions and qualitative multifunctional performance to assess their potential in terms of multi-functionality (flood control for small and large events, ecology, social) and land use. Thereby it should be considered that the real performance depends not least on local conditions, the right design and maintenance of UGI elements.

Table 3: Green Infrastructure elements and their multifunctional performance (based on information from [24-35]); ++ = very high, + = high, o = medium, - = low/none

\begin{tabular}{|c|c|c|c|c|c|}
\hline Storm water tree & + & - & ++ & + & $\mathrm{o}$ \\
\hline Bioretention area & + & $\mathrm{O}$ & + & ++ & - \\
\hline Swale & + & $\mathrm{o}$ & + & + & - \\
\hline Infiltration trench & + & $\mathrm{O}$ & $\mathrm{O}$ & $\mathrm{o}$ & $\mathrm{O}$ \\
\hline
\end{tabular}

* Comment: Expected performance based on the literature studied and qualitative classification by the author of this work. It must be noted that the performance is highly dependent on the design of the element and subsequent maintenance measures.

UGI elements as on-site features are normally intended to control smaller and short to medium duration events. But some systems with greater surface, as basins and constructed wetlands, can also cater larger storms. Others have a reduced performance during long wet periods as permeable pavements and storm water trees. In terms of ecological performance, especially elements with the possibility of intensive planting are classified as high. Larger vegetated UGI elements as basins and constructed wetlands generally can count therefore on a higher value. In the social dimension, especially bio retention areas designed as smaller systems can be integrated as traffic regulating measures along streets. No additional land is necessary by implementing permeable pavement since multiple functions can be easily united in one location. Infiltration trenches only need minimal extra land when well designed, as small width and narrow shapes are possible. In the study area, they can be incorporated in the existing street curb. In comparison bio retention areas and storm water trees need more width. Significant land take is necessary for swales by reason of their shallow side slopes and much land is in demand for larger elements as basins.

Table A3 in Appendix A shows the selected elements by their proposed hydrologic function and main intentions when implemented in the study area. Placement criteria are derived from 
recommendations from international and local guidelines as well as characteristics of the elements [2434]. The principle is to build on existing structures as a way of retrofitting. So, existing green verges in the road system are used to avoid complete unsealing. From the placement criteria in turn suitable spatial ty pologies (see Step 3) for each element are derived. The dimensions are based on the actual availability of space in the study area. How ever, the individual elements could also be designed in other dimensions.

\section{Results and discussion}

\subsection{Multi-functionality - hydrological dimension}

The implementation of different UGIs along the whole management train (source-control, conveyance, and retention or end-control), as recommended in several manuals and studies [18,39-41], was defined as a principle strategy to achieve an improvement in the criteria "runoff control" of the hydrological dimension of multi-functionality. Such a management or treatment train with a number of small, but interconnected elements can counteract the risk of over-dimensioning individual GI elements in contrast to stand-alone UGI [41] and is the only means of meeting multiple design criteria [35].

Within the study area, different placement possibilities based on Table A3Error! Reference source not found. for decentralized source-control elements such as permeable pavements, conveyance elements as infiltration trenches and bio retention areas in the road system as well as individual endcontrol measures at larger open spaces were identified. To control runoff of lager storm events, how ever, UGI elements in form of end-control measures placeable at larger open spaces next to the river course showed to be most effective. In the study area, this is possible only in sub-basins (1), 2, 4, 6 and 7 as revealed in the site analysis (Step 1 ). In the other sub-basins, a control of the outflow is only possible to a small extent with decentralized measures through source-control and convey ance elements within the road system.

Sub-basin 2 (see Figure 4), representing the largest sub-basin of the study area with a size of 9,6 ha, was chosen to demonstrate the hydrological dimension of the multi-functional potential of UGIs through the application of our methodology to identify potential sites and placements. The maximal possible implementation of UGIs in this sub-basin was analyzed using the total storage capacity and potential runoff reduction as hydrological performance indicators as recommended by Wang, Pauleit et al. [35]. Table 4 summarizes the identified UGIs suitable for sub-basin 2 in kind, amount or length as well as the individual and accumulated (total) storage capacity of all elements.

Table 4: Kind, a mount or length as well as the individual and accumula ted (total) storage ca pacity of all identified UGIs suitable for sub-basin 2.

\begin{tabular}{|c|c|c|c|}
\hline UGI element & $\begin{array}{c}\text { Number or length of } \\
\text { elements }\end{array}$ & Storage capacity $\left[\mathrm{m}^{3}\right]$ & Total storage capacity $\left[\mathrm{m}^{3}\right]$ \\
\hline Storm water tree & 13 elements & 1,8 & 24 \\
\hline Bio retention area & 7 elements & 16,8 & 118 \\
\hline Infiltration trench & 316 meters & 0,27 per meter & 85 \\
\hline Detention basin & 1 element & 1.394 & 1.394 \\
\hline Constructed wetland & 1 element & 884 & 884 \\
\hline Total & & & 2.505 \\
\hline
\end{tabular}

The underlying calculations of storage capacities and drainage areas for Table 4 are presented in Table A1 and A2 in the appendix. Figure 9 visualizes the potential placement of UGIs in sub-basin 2. 


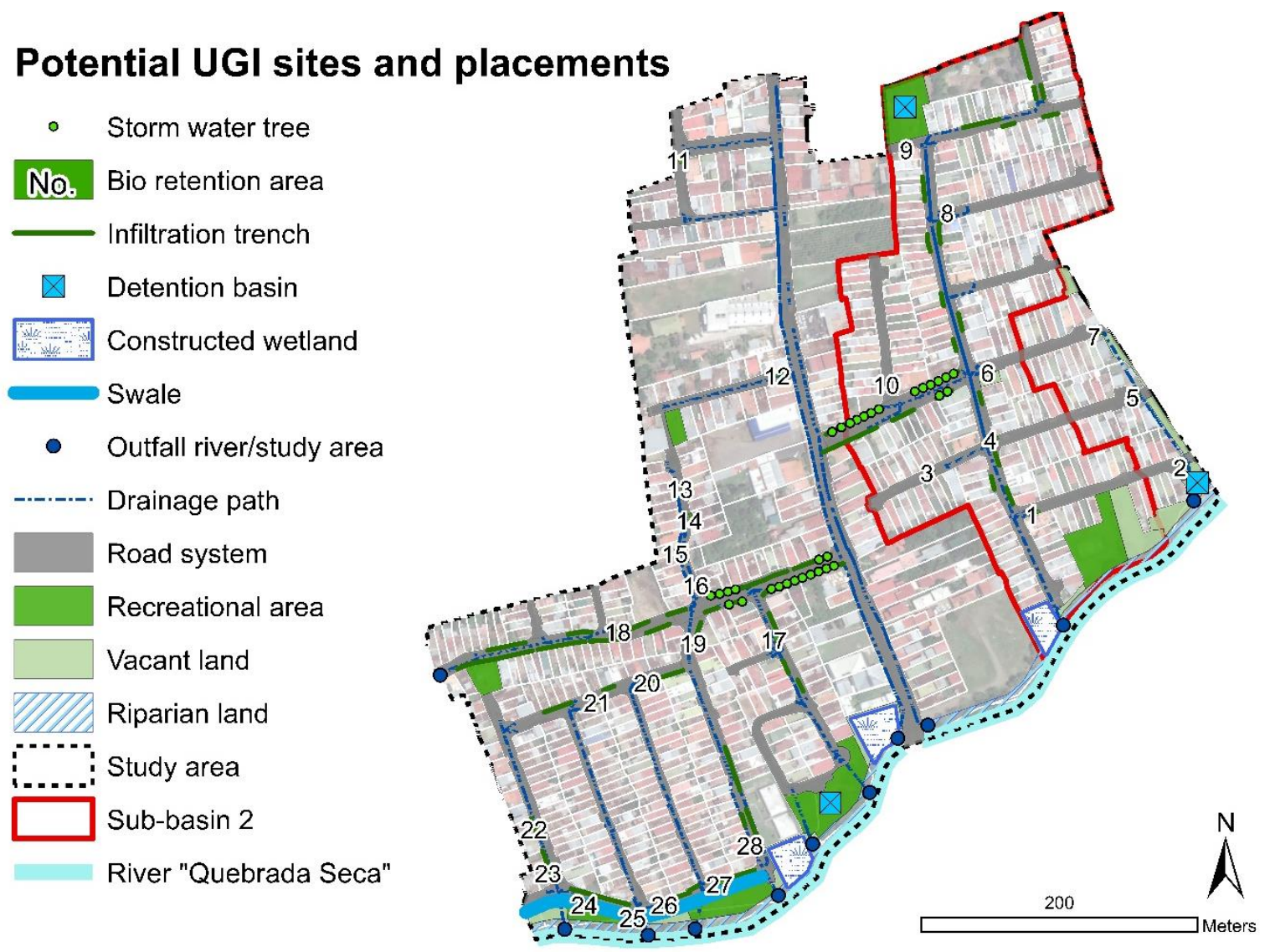

Figure 9: Potential UGI sites and placements to achieve the hydrological dimension of multifunctionality.

To calculate the storage capacity, it was assumed that there was no antecedent rainfall and therefore the soil was not saturated. The calculation leads to a theoretical total storage capacity of around $2.505 \mathrm{~m}^{2}$ for all elements. Especially the larger (end-control) UGI elements on open spaces contribute the largest storage capacities. The conveyance elements along the road system, on the other hand, contribute only with small storage volumes to the total value.

The potential runoff reduction for different return periods of rainfall was calculated based on respective rainfall amounts (in $\mathrm{mm}$ ) and the size of the area (9,6 ha) to determinate the volume of surface runoff. The total storage capacity of the UGI elements $w$ as then divided with the surface runoff volume to get the potential runoff reduction in \% (see Table 5).

Table 5: Rainfall characteristics and storage potential of UGI elements proposed for Sub basin 2.

\begin{tabular}{|c|c|c|c|c|}
\hline Rainfall TR (year) & $\begin{array}{c}\text { Rainfall amount } \\
{[\mathrm{mm}]}\end{array}$ & $\begin{array}{c}\text { Runoff rainfall } \\
{\left[\mathrm{m}^{3}\right]}\end{array}$ & $\begin{array}{l}\text { Total storage } \\
\text { capacity }\left[\mathrm{m}^{3}\right]\end{array}$ & $\begin{array}{c}\text { Potential runoff } \\
\text { storage }(\%)^{1}\end{array}$ \\
\hline 2 & 78 & 7.472 & 2.505 & 34 \\
\hline 5 & 98 & 9.385 & 2.505 & 27 \\
\hline 10 & 113 & 10.820 & 2.505 & 23 \\
\hline
\end{tabular}

${ }^{1}$ performance depends not only on the storage capacity and size of dra inage area, but also on the rainfall characteristics, the slope of the area as inflow characteristics and the type of vegetation.

Hence, for the design criteria runoff control between $23-34 \%$ of total storm water runoff reduction, depending on the considered rainfall event, can be achieved in the exemplary sub-basin. Moreover, five different UGI elements of the management train; fulfilling functions of source-control, filtration, retention/detention, convey ance-, and end-control; could be implemented.

Since pluvial flooding is not an issue in the study area because of the pronounced topography (average slope $7 \%$ ), the storm water runoff reduction is more relevant for a decrease of downstream fluvial flood problems. In a densely urbanized area as the studied one, the implementation of a 
combination of several retrofitted runoff reduction measures at suitable distributed sites are necessary to achieve a notew orthy effect. This has been confirmed also by other studies $[17,43]$.

The storm water runoff reduction described above represents the maximum hydrological potential of UGI in the sub-basin and therefore only on dimension of multi-functionality to be considered.

The detailed hydrologic response, effectiveness and the cumulative effects of a series of elements and the proposed UGI elements could be further investigated through modelling, using for example the EPA Storm Water Management Model (SWMM), a dynamic rainfall-runoff simulation model simulating both water quality and quantity of urban storm w ater runoff for single events and long-term simulation of small urban catchments [44]. As it is done in other studies for different UGI elements and combinations at the city and district scale [45,46], but mainly for urban environments in developed countries. Modelling can provide a cost-effective alternative compared to real monitoring of the performance of UGI elements in the field [12]. These could be also made in developing countries, taking into account different design considerations and field conditions.

The management train could also be supplemented with more source-control elements at property level, such as the RWH systems. Further exemplary possibilities are green roofs or raingarden as alternative design options of bio retention areas. In the road system, the possibilities of source-control elements, as the first level of the management train, are rather difficult. For storm $w$ ater trees as a standalone feature only few potential locations were found and permeable pavements are only considered to be useful in the context of reconstruction measures, as unsealing on larger-scale is not recommended.

\subsection{Multi-functionality - ecological dimension}

For the ecological dimension of the multi-functionality of UGIs in the study area, the specific design of UGI elements (biodiversity-friendly plant selection and planting, use of vegetated above ground elements where possible, use of GI of higher ecological value) as well as their placement (increasing connectivity between existing green spaces, development of a continuous roadside greenery netw ork) matters.

The integration of vegetated above-ground elements in the road system and the develop of a roadside greenery network can be accomplished, in general, though all proposed UGI measur es as all of them can be vegetated and therefore contribute (when right-planted and designed) to the enhancement of biodiversity. Nevertheless, larger elements are assumed to have a higher ecological value [47]. This w ould be the case with bio retention areas within the road system. The development of the roadside greenery netw ork, when referring to trees, is on the other hand rather limited in terms of space in the study area. Linear elements in the road system can contribute to the ecological connection of green spaces, especially infiltration trenches. Another strategy was to select UGI elements with expected high ecological value in creating new habitat types, which are especially larger end-control elements [35,36,40,48]. Properly designed and later maintained, these are in our study area mainly constructed wetlands in the proximity to the river. Three potential sites for constructed wetlands were identified within the study area (Figure 9). The implementation of these wetlands would create new aquatic habitats along the river corridor. After implementation and in operation, a range of biological investigations could measure the value of the ecological aspect of UGI with regard to biodiversity improvement. Important is, when implemented, the occurrence, abundance, range and species richness of wild pollinators and biological control agents.

The evaluation of improvements in the ecological multi-functionality dimension (criteria biodiversity enhancement) due to the proposed UGI elements can at this planning stage be realized with regard to [0-100] \% increase of green space, [m] length of roadside greenery created, $\left[\mathrm{m}^{2}\right]$ area of vegetated above ground elements created, and $\left[\mathrm{m}^{2}\right]$ of new habitat types created. The results a re summarized in Table 6. 
Table 6: Evalua tion of indicators of the ecological dimension of multi-functionality.

\begin{tabular}{|c|c|c|}
\hline $\begin{array}{c}\text { Indicator of ecological multi- } \\
\text { functionality dimension }\end{array}$ & $\begin{array}{c}\text { Achievement through full } \\
\text { UGI implementation }\end{array}$ & Remarks \\
\hline $\begin{array}{c}\text { Increase of green space } \\
\text { (excluding riparian land) [\%] }\end{array}$ & 2,2 & $\begin{array}{c}\text { Additional green space provided by bio } \\
\text { retention areas and storm water trees }\end{array}$ \\
\hline $\begin{array}{c}\text { Length of roadside greenery } \\
\text { activated [m] }\end{array}$ & 1,500 & $\begin{array}{c}\text { Infiltration trenches and storm water } \\
\text { trees }\end{array}$ \\
\hline $\begin{array}{c}\text { Area of vegetated above } \\
\text { ground elements created [m }\end{array}$ & $\begin{array}{c}2.446 \mathrm{~m}^{2} \text { of wetland area, } \\
2.948 \mathrm{~m}^{2} \text { of bio retention areas, } \\
99,2 \mathrm{~m}^{2} \text { of storm water tree pits }\end{array}$ & $\begin{array}{c}3 \text { constructed we tlands, } \\
28 \text { bio retention areas, } \\
\text { 32 storm water trees }\end{array}$ \\
\hline New habitat types created [-] & 3 & Constructed wetlands \\
\hline
\end{tabular}

These evaluation indicators are of course only area- and land cover related, quantitative proxies of biodiversity enhancement and do not express the qualitative value of habitat nor the quantitative increase in species or genetic diversity. During the design process it is hard to measure the future level of biodiversity of the proposed UGI elements. In general, the choice of planting has a great influence on the ecological value of the UGI element. Therefore, generally biodiversity-friendly right planting is recommended among all UGI measures. Also, with an adapted design the ecological value of the proposed UGI elements might be even increased. Despite this Monberg, Howe et al. [49] developed an index score for different vegetated above-ground types of UGIs reflecting the structural heterogeneity potential and thereby the habitat provision in urban green areas to assess potential ecological benefits of different UGI designs. In their study, it could be shown, that with an adapted "bio-design", which means the employment of e.g. deadwood, terrain differences, stones, etc. the ecological value of standard UGIs can be greatly increased among all investigated elements (infiltration trenches, bio retention areas as curb extension, raingardens, sw ales, dry and wet basins) [49]. Which means, that a change in design aw ay from the classic standard (hydrological/hydraulic) design can have a major impact on the ecological value of a UGI element.

From an ecological point of view, it may make sense to combine and supplement the engineered elements investigated in this w ork with other classical green features like simple street green with native vegetation, community gardens, urban parks and forests as well as a restored river corridor. They are principally easier and simpler to implement and need less technological know -how, but may have a large impact on the urban biodiversity of the site. But also, green roofs are classified as ecologically valuable in the literature (see e.g. Cvejic, Eler et al. [49]). There is commonly a large potential of roof area in residential neighborhoods as in the case of our study area. We limited our study to public space, roof tops in residential areas are private properties and implementation and promotion of UGI such as green roofs or rainwater harvesting would require different policy and financing mechanisms. How ever, significant ecological gains are possible when considering the roof area.

Further benefits beside enhanced biodiversity and habitat creation can be expected from the UGI elements after implementation. Thus, UGI implementation can also bring further advantages for the study area. One often occurring problem due to a high degree of urbanization are urbanheat islands. A surface-wideimplementation of UGI elements and especially the planting of trees, distributed over the surface, can counteract this and regulate the local climate [50].

\subsection{Multi-functionality - Social dimension}

With regard to the social multi-functionality dimension, one strategy in our study area was to integrate UGI right-located to calm traffic with the aim to increase safer accessibility to public (green) space. Of all considered UGI elements, bio retention areas are the most suitable for this purpose since sites for their implementation are not limited by vertical space requirements as in the case of storm $\mathrm{w}$ ater trees. In the study area there are many potential placements of these elements in the road system designed as curb extensions for traffic calming (see Figure 7). In addition, these elements can be used specifically to create additional space for other uses such as outdoor seating or where particularly safe street crossing is demanded. Since bio retention areas are very flexible in their design, further implementations are also possible. Within the scope of this w ork, the elements designed as pinch points 
or chicanes in street design were shown as a punctual area element. A narrower linear implementation would also be possible, e.g. acting as a lane shift element, also functioning as traffic calming elem ent (see Figure 10).

However, the current road design, traffic volume and general prioritization of motorized traffic results in many limitations to the implementation of larger and more restrictive UGI elements in the road system. But if communities are willing to implement UGI elements, their implementation can offer a great opportunity to redesign the existing traffic concept. Municipalities could act a s a role model and undertake an offensive redesign also with the help of UGI elements. Roads could be designed to reduce traffic through spatial restrictions, e.g. one-w ay streets could be created and thus the possibilities of UGI implementation in the road system could be greatly expanded. The following map with illustrated design examples from the US National Association of City Transportation Officials (NACTO) [50] shows an example of the possibilities in the study area for a radical redesign of the existing road system (see Figure 10). This would create possibilities to change the behavior of road users, aw ay from motorized traffic and towards more pedestrians. A survey in the study area showed, that the majority of the surveyed inhabitants welcome more green areas on the one hand, but on the other hand do not want a restriction of car designated areas [51]. But it is suggested, that people adapt to their conditions, therefore human behavior, which governs traffic engineering, is principally adaptable and not fixed through a proactive design [51].

The so-called "green streets" in Figure 10 could be designed as shared streets, which although allowing access for residents with motorized traffic, could be designed in a traffic calming manner, thus providing more space for other road users such as cyclists and pedestrians on the roads. The road lanes could be designed narrower, thus providing space for GI elements, wider green spaces, cycle paths, marked parking areas, etc.

\section{Redesign of the road system}

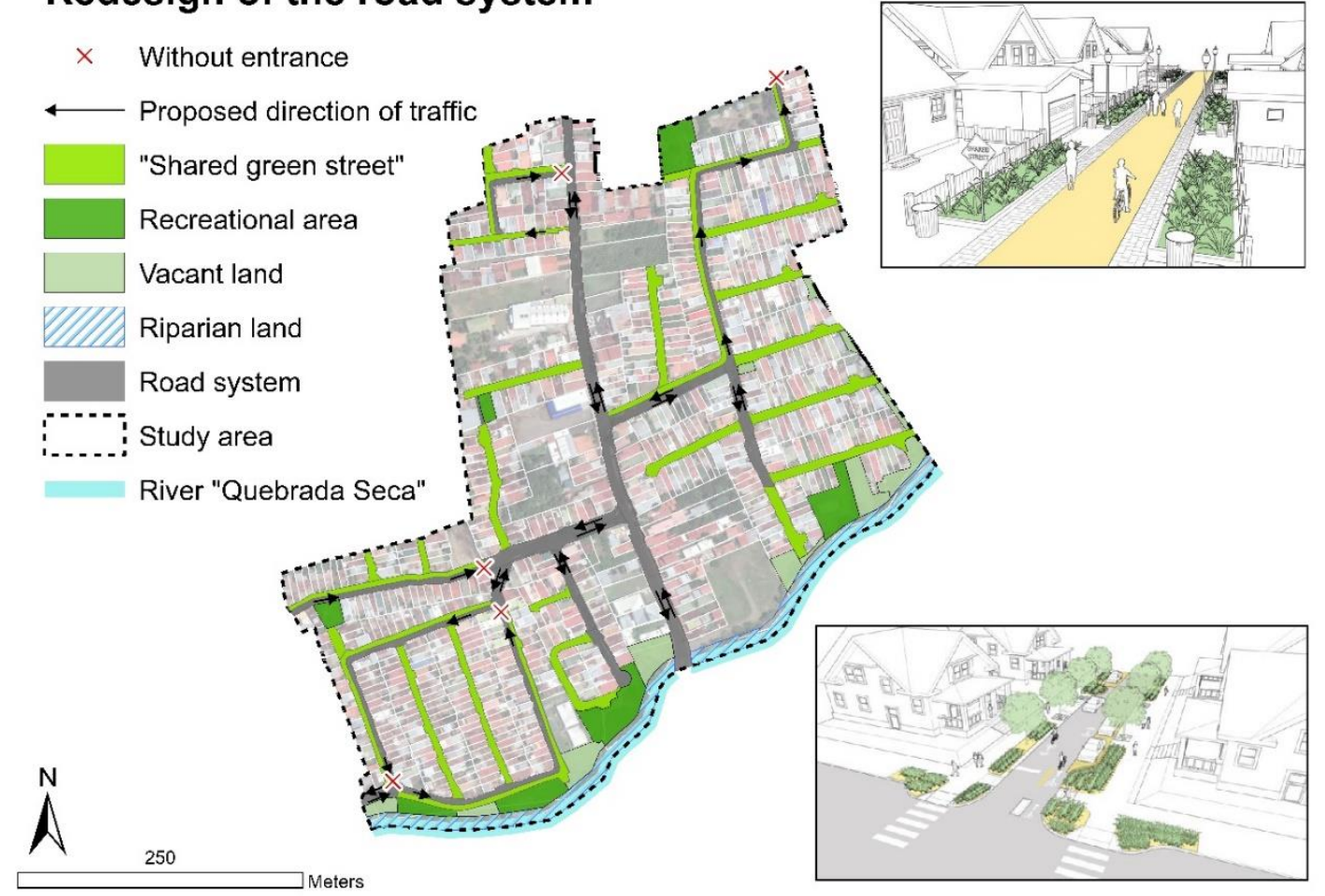

Figure 10. Proposal for a redesign of the road system in the study area in order to improve the social dimension of multi-functionality (Source of images: https://nacto.org/publication/urban-street-designguide/).

When thinking about a network, another strategy is to increase or provide physical connections between green spaces. In our study area, green spaces are mainly located along the river corridor, but fragmented, due to fencing and a close built environment. A field screening of the area showed, that connecting them is difficult to achieve. However, the proposed physical connection could provide a 
good opportunity to integrate the constructed wetland, create links between urbanizations and ensure a pedestrian-friendly crossing over the main road of the site.

From a social point of view, many more benefits besides better accessibility can be expected from GI elements after implementation. Principally in the study area, when implemented in vacant land, new recreational spaces can be created, but also existing recreational areas could be converted in parks for recreation for all age groups of residents. The proposed UGI elements could be further seen, among others, as an opportunity for environmental education, reconnection to nature, and social cohesion tow ards healthy urban living in the study area.

Accessibility is in our study the prioritized criterion for the social functionality dimension. It is related to the placement and design of UGI with the aim to calm traffic for better and safer walkability as well to increase the physical connection to green spaces for recreation. The purpose is to encourage active travel, outdoor activities, and recreation within a neighborhood [21]. The criteria of accessibility was evaluated with the $[\mathrm{m}]$ length increase of roads with improvement in road category (Table 7 ).

Table 7: Evaluation of road type change due to proposed redesign of the road system in the study area.

\begin{tabular}{|c|c|c|}
\hline Change of road type & $\begin{array}{l}\text { Length of road type } \\
\text { change }[\mathrm{m}]\end{array}$ & UGI traffic calming options gained due to road type change \\
\hline $2 \rightarrow 3$ & 350 & Bio retention area, swale, storm water trees \\
\hline $3 \rightarrow 4$ & 750 & $\begin{array}{l}\text { Bio retention area, swale, storm water trees, permeable } \\
\text { pavement }\end{array}$ \\
\hline $4 \rightarrow 5$ & 100 & Permeable pavement \\
\hline
\end{tabular}

\subsection{Overall discussion}

The previous sections revealed that there is potential of UGI placements to achieve the different dimensions of multi-functionality. In general, it could be noted, that in literature often only the hydrological aspect is considered. Therefore, also modelling tools mainly address the assessment of water quantity and quality criteria, while such tools to assess biodiversity and social values, delivered by UGI elements, are generally not available to the same degree. But considered as a unit, it must be stated, that each criterion is important to consider during design. As also Lähde, Khadka et al. [18] suggests, "if biodiversity criteria have failed, it has a degenerative impact on both the amenity and water quantity management potential of the site". Which in turn means, that if the delivery of multifunctional benefits is not considered during the design process, this could ruin any chances of achieving goals related to multi-functionality [18]. Therefore, methods for the assessment of complex criteria and complete understanding of multi-functionality need further development. Decision-making and selection of adequate UGI elements is a difficult task due to complex interactions between natural, social and built environments. In the context of the present work, a possibility was found, using the example of a study area, to consider the different dimensions of multi-functionality with the selection of suitable UGI elements and the analysis of possible placements and geometries considering the spatial features of the site. The information on spatial conditions in this study area is very detailed, therefore also a detailed investigation could be undertaken in this case. Nevertheless, the procedure to analyses the space availability of a study area regarding existing traffic and green spaces can generally be adapted to other similar areas, even with less data, tow ards sustainable urban transitions.

The analysis of spatial typology (road system and open space characterization as well as site specific constraints, e.g. driveways), as proposed in our methodological approach, is helpful and establishment of multi-functional design criteria and related implementation strategies can reveal the placement potential for UGI and provide guidance for efficient implementation at the neighborhood level. By the use of quantitative indicators for different design criteria, the potential impact can be estimated and compared to traditional/conventional (grey) solutions. To think beyond hydrological functioning of UGI can lead to significant multi-functionality gains. Especially, beneficial on-site functionalities of a strategic placement of multifunctional UGI can deliver additional arguments to the often off-site (downstream) perceived benefits of runoff control.

When looking at specific UGI elements, bio retention areas can be placed multi-functionally as a traffic regulating element in principle at many locations in the study area. The element infiltration trench 
offers great possibilities, if the road design is not to be changed. For constructed w etlands three suitable sites are found in the study area, which could offer, as end-control elements, a certain retention even during larger storm events for the respective sub-basins and further could be used for greywater treatment.

The suitable open spaces for implementing GI elements, considered in the actual analysis, correspond to $10 \%$ of the total area. Basically, implementation options are alw ays limited to the space availability onsite. Further opportunities can arise if more usable areas are created, for example, through the conversion of undeveloped properties, where the community can reach an agreement with landowners. Undeveloped properties account for $6 \%$ of the total area. This would also provide more opportunities for larger conveyance elements for more runoff control on-site in the study area and not just large-scale elements along the river, which w ould alw ay s act as an end-of-pipe solution.

In general, more possibilities should be exploited by implementing elements in the road system, as $17 \%$ of the total area in the study area correspondents to roads. UGI elements offer many multifunctional possibilities there. Even if the hydrological benefits are limited to the retention and reduction of runoff directly falling on the element (source-control) or to the first-flush, nevertheless, at least smaller rainfall events can be controlled. Whereas, in the ecological and social dimensions, greater benefits can be expected. Among others, the green network on smaller scale with individual decentralized measures can be developed, which contributes to the biodiversity on-site, as well as UGI elements right placed can function as traffic regulating elements, change the traffic behavior of residents, provide more safety and accessibility in the area, aesthetically enhance the space and counteract the heat island effect. The analysis shows, that many different measures can be integrated into the road system, no matter, if the street design should be changed and its traffic restricted or if the current conditions are only used; whereby storm water trees, bio retention areas and infiltration trenches are suggested as the most suitable ones. All in all, potential of implementing UGI measures are given for the whole road hierarchy and all traffic volumes among the study area. The many existing green verges in the road system can be used well for implementing UGI elements there and thus the runoff is not just passed by, as it is at present. And as a result, additional unsealing is reduced or not necessary at all.

Due to the flexible design of bio retention areas, this type of UGI in particular could offer many possibilities. These can be designed as an areal or linear element, as a transport element in the road system, but also in principle on properties themselves or open spaces as a larger (end-control) element. Correctly placed, the elements could be used as traffic calming technology in the road design. Here, many different configurations are possible. Designed as bio filter, a further treatment of greywater is also possible.

When selecting the right UGI elements and their location, the aspects of multi-functionality should not be neglected. In general, the hydrological aspect should not be considered alone, as it is mainly done among literature. The present w ork could show, that UGI elements can simultan eously offer many other positive aspects for urban areas. Last but not least, they provide an opportunity to reconsider the existing road design and create more recreational areas for residents. Also, properly designed UGI elements can contribute to urban biodiversity and create habitats.

In principle, a combination of different measures in the management train is recommended. This is suitable, not only in the hydrological sense, but also in the ecological one. Vegetated UGI elements, as smaller green spaces decentralized on properties and distributed over the road system, together with larger green areas and ecologically particularly valuable elements on them, result in a woven green netw ork over the entire area, that can have a strong positive effect on the urban biodiversity of the site.

A combination is also recommended in the social sense. Voluntary commitment and participation of residents in UGI promotion can be achieved at the property level, for example, when people choose for their own to collect rainwater in RWH systems. In the road system, the elements can contribute among others to the safety of residents and, in larger areas, to more recreational areas. But this work did not consider the possibilities of UGI on properties themselves. Nevertheless, in the literature, especially for densely urbanized areas, the opportunities for UGI implementation on properties themselves are estimated as valuable. Often, green roofs are recommended, which are also considered useful in terms of their ecological benefits. According to this, the use of rainw ater by RWHsystems, and further UGI elements (e.g. raingardens) as prevention measures and first stage of the management train 
could be promoted more, as it is also undertaken by the Municipality of Curridabat, Costa Rica, for small-scale UGI on private lots [52]. In the case of green roofs, however, particular building specifications are required to support the additional weight from the plants and substrates, therefore they are probably more likely to be implemented in future building projects, rather than existing ones as retrofitting measures.

The present work showed, that retrofitting is often difficult and associated with many uncertainties and restrictions in planning. Often extensive unsealing must take place and major changes to the street design could lead to later conflicts with the residents. In contrast, implementation is considered easier, cheaper and more probable in the case of reconstruction measures. Therefore, it is recommended, that municipalities already consider multifunctional UGI elements in the planning of new urban areas. Permeable surfaces could be used right from the start as pavements in areas with low traffic volumes, storm $w$ ater trees for temperature regulating, bio retention areas to control traffic in a targeted manner, larger collective storage facilities to create green spaces and urban parks. In the case of the municipality of Flores, such considerations could be applied to the expansion of the residential area to the "undeveloped land - east". Simultaneously, legal principles should be created and policy instruments, depending on the responsibility, as the "plan regulador" in Costa Rica used.

\subsection{Our methodology in the context of other recent studies}

Kuller et al. (2019) have developed and tested a placement tool for UGI for Australia, but it is focused on hydrological functioning and not considering specific constraints of urban road design of less developed countries [53]. Also Giacomoni and Joseph (2017) presented a study on UGI placement optimization, but again with a narrow hydrological focus [54]. A study of Hasala et al. (2020) presents an approach of participatory mapping to assess local perceptions of nuisance flooding [55]. Their approach goes beyond hydrological design principles and includes residents' perceptions of potential benefits. Still multi-functionality in UGI placement, as in our methodology, is not considered.

For a city-wide scale, Tran et al. (2020) propose the Green Infrastructure Space and Traits (GIST) model, a planning tool for evaluating and maximizing UGI multi-functionality based on optimizing both site selection and plant traits in UGI design [56]. Their derivation of multiple benefits based on plant characteristics could possibly also be partly applied as additional functionality indicators in our spatially explicit neighborhood scale methodology. We suggest to consider this in future investigations.

For a developing country context, Nugroho et al. (2019) determined in their study the placement of UGI in accordance with the criteria of land suitability and analyzed the effectiveness of its application for an urban catchment of Jakarta, Indonesia [56]. Bio retention and rain barrels were identified as suitable UGI elements and their effectiveness in runoff reduction could be proved by modelling. How ever, other functional dimensions, such as social or ecological, were not assessed.

With regard to the functionality of micro-climate regulation, Norton et al. [50] presented a framew ork that enables prioritization of placement and UGI type at the neighborhood scale. Since this functionality of the social dimension w as not considered in our study, it could be promising to integrate or combine their and our placement methodologies to represent another form of UGI multifunctionality.

\section{Conclusions}

Urbanization has increased the volume and peak flows of storm water runoff, exposing communities to greater risks of floods. In the future, climate change will further increase the extremities of storm events. Thereby green spaces, reduction of impervious surfaces and UGI as storm water retention facilities can meet this problem, while at the same time enhance the ecological function of urban spaces and bring many social benefits in promoting sustainable living. UGI elements are considered a benefit for territorial development because they provide multiple functions within the same spatial area. This w ork investigated the realistic potential of multifunctional UGI placement at the neighborhood scale for a tropical country. For this purpose, an exemplary area was spatially investigated, suitable multifunctional design criteria and strategies were defined, and on the basis of the available space, spatial possibilities for various suitable UGI elements regarding their placement, spatial distribution and geometries were investigated. 
This work is intended to show possibilities for GI elements in relation to the study area by means of a generally developed method, nevertheless, when it comes to real implementation, further exact investigations in the field and modelling are essential. It could be stated, that even for densely populated areas there are many opportunities of implementation. Especially the road system should not be neglected. Different UGI elements should be combined, to not at least, provide better control on all levels of the management train, respectively of an entire spectrum of storm events, and to exploit the full range of potential environmental and social benefits.

The proposed and exemplified methodology presented in this w ork can guide local planners and decision-makers in their actions of UGI implementation at the neighborhood scale. Through a detailed analysis of local preconditions and with site-specific design criteria, the multifunctional benefits from UGI could thereby even be increased. A careful coordination of the interdependences of the different aspects of multi-functionality and other urban functions in the design process is essential, if UGI elements are to be successfully implemented in a densely urbanized area. Nevertheless, this work showed, that considering all dimensions of multi-functionality requires a structured and strategic approach.

Therefore, one possibility in the future w ould be to design a multi-criteria web tool to assist in the screening and selection of measures adapted to the climatic conditions in tropical developing countries. But it is questionable to what extent further multifunctional advantages of GI can be taken into account. At least, the development of UGI design guidelines adapted to the respective data situation on site and local conditions is considered to be useful, since these, so far, only exist for developed countries. There, local difficulties such as on-street, untreated greyw ater runoff or the demand for low -cost UGI solutions could be better taken into account and incorporated into design specifications of GI elements. All in all, many ecological and social problems of urban areas in tropical developing countries could possibly be counteracted with engineered UGI elements: Existing drainage systems can be relieved, the problem of flooding countered, the sealing of the area reduced, public green recreation areas created, the heat island effect reduced, other traffic participants like pedestrians supported, and untreated greyw ater purified. Thus, the concept of UGI offers many possibilities far bey ond the hydrological aspect, not only for highly industrialized countries, but also for Costa Rica and other less developed countries. Last but not least, the involvement of policy, local responsibility and the population is required. Thereby social acceptance, creation of local knowledge, and available budget are essential basic requirements for successful UGI projects. Thus, UGI elements may become an integral part of spatial planning and territorial development, as they often offer a better alternative to standard grey solutions by providing multiples functions.

Author Contributions: Conceptualization, T.F. and J.H.; methodology, T.F. and J.H.; software, T.F.; validation, T.F. and J.H.; formal analysis, T.F. and J.H.; investigation, T.F. and J.H.; re sources, T.F. and J.H.; da ta curation, T.F.; writing - original draft preparation, T.F. and J.H.; writing - review and editing, T.F. and J.H..; visualization, T.F.; supervision, J.H.; project adminis tration, J.H.; funding a cquisition, J.H.

Funding: This research was funded by the German Federal Ministry of Education and research (BMBF), grant number 01UU1704.

Acknowledgments: We acknowledge support from the German Research Foundation (DFG) and the Open Access Publishing Fund of Technical University of Darmstadt.

Conflicts of Interest: The authors de cla re no conflict of interest. 


\section{Appendix A}

Table A1: Overview of storage capacity calcula tions for considered UGI.

\begin{tabular}{|c|c|c|c|}
\hline UGI element & Formula & Calculation & Average storage capacity \\
\hline $\begin{array}{l}\text { Storm water } \\
\text { tree }\end{array}$ & $\begin{array}{l}\text { Area per element }\left[\mathrm{m}^{2}\right] * \\
((\text { Depth of system }[\mathrm{m}] * \\
\text { Void volume of filled } \\
\text { substrate mixture }[\%])+ \\
\text { ponding depth }[\mathrm{m}])\end{array}$ & $\begin{array}{c}(1,75 \mathrm{~m} * 1,75 \mathrm{~m}) *((1,0 \mathrm{~m} * 0,5)+ \\
0,1 \mathrm{~m})\end{array}$ & $1,8 \mathrm{~m}^{3}$ \\
\hline $\begin{array}{l}\text { Bio retention } \\
\text { area }\end{array}$ & $\begin{array}{c}\text { Area per element }\left[\mathrm{m}^{2}\right] * \\
((\text { De pth of soil }[\mathrm{m}] * \\
\text { Void volume soil }[\%])+ \\
\text { (Depth of gra vel }[\mathrm{m}] * \\
\text { Void volume gravel } \\
[\%])+ \text { depth of ponding } \\
[\mathrm{m}])\end{array}$ & $\begin{array}{c}30 \mathrm{~m}^{2} *((0,2 \mathrm{~m} * 0,7)+(0,8 \mathrm{~m} * \\
0,4)+0,1 \mathrm{~m})\end{array}$ & $16,8 \mathrm{~m}^{3}$ \\
\hline $\begin{array}{l}\text { Infiltration } \\
\text { trench }\end{array}$ & $\begin{array}{c}\text { Average area per } \\
\text { element }\left[\mathrm{m}^{2}\right] *((\text { Depth } \\
\text { of soil layer }[\mathrm{m}] * \text { Void } \\
\text { volume soil }[\%])+ \\
\text { (Depth of gravellayer } \\
{[\mathrm{m}] * \text { Void volume }} \\
\text { gravel[\%])) }\end{array}$ & $\begin{array}{c}(0,5 \mathrm{~m} * 27,8 \mathrm{~m}) *((0,2 \mathrm{~m} * 0,7)+ \\
(1,0 \mathrm{~m} * 0,4))=7,5 \mathrm{~m}^{3}\end{array}$ & $7,4 \mathrm{~m}^{3}\left(=0,27 \mathrm{~m}^{3}\right.$ per meter $)$ \\
\hline $\begin{array}{l}\text { Detention } \\
\text { basin }\end{array}$ & $\begin{array}{c}\text { Available open space } \\
{\left[\mathrm{m}^{2}\right] * \text { Average depth of }} \\
\text { element }[\mathrm{m}]\end{array}$ & $1.245 \mathrm{~m}^{2 *} 1,12 \mathrm{~m}$ & $1.394 \mathrm{~m}^{3}$ \\
\hline $\begin{array}{l}\text { Constructed } \\
\text { wetland }\end{array}$ & $\begin{array}{c}\text { Available open space } \\
{\left[\mathrm{m}^{2}\right] * \text { Average depth of }} \\
\text { element }[\mathrm{m}]\end{array}$ & $850 \mathrm{~m}^{2 *} 1,04 \mathrm{~m}$ & $884 \mathrm{~m}^{3}$ \\
\hline
\end{tabular}

Calculated with dimensions from Table A2. Soil and gravel layer depth according to [42].

Table A2: Overview of drainage a rea calculations for considered UGI.

\begin{tabular}{|c|c|c|c|}
\hline UGI element & Formula & Calculation & Average drainage area \\
\hline $\begin{array}{c}\text { Storm water } \\
\text { tree }\end{array}$ & $\begin{array}{c}\text { Average flow length } \\
\text { [m] * Average width of } \\
\text { drainage area }[\mathrm{m}]\end{array}$ & $7,8 \mathrm{~m} * 25,5 \mathrm{~m}$ & $197,6 \mathrm{~m}^{2}$ \\
\hline $\begin{array}{c}\text { Bio retention } \\
\text { area }\end{array}$ & $\begin{array}{c}\text { Average flow length } \\
{[\mathrm{m}] * \text { Average width of }} \\
\text { drainage area }[\mathrm{m}]\end{array}$ & $46,2 \mathrm{~m} * 23,5 \mathrm{~m}$ & $1.085,7 \mathrm{~m}^{2}$ \\
\hline $\begin{array}{c}\text { Infiltration } \\
\text { trench }\end{array}$ & $\begin{array}{l}\text { Average flow length } \\
{[\mathrm{m}] * \text { Average width of }} \\
\text { drainage a rea }[\mathrm{m}]\end{array}$ & $35,5 \mathrm{~m} * 23,5 \mathrm{~m}$ & $834,3 \mathrm{~m}^{2}$ \\
\hline $\begin{array}{l}\text { Detention } \\
\text { basin }\end{array}$ & $\begin{array}{c}\text { Entire drainage area } \\
\text { upstream from } \\
\text { placement site }\end{array}$ & - & 1,6 ha \\
\hline $\begin{array}{l}\text { Constructed } \\
\text { wetland }\end{array}$ & $\begin{array}{l}\text { Entire drainage area } \\
\text { upstream from } \\
\text { placement site = Sub- } \\
\text { basin area }\end{array}$ & - & 9,6 ha \\
\hline
\end{tabular}


Table A3: Overview of UGI elements and their characteristics

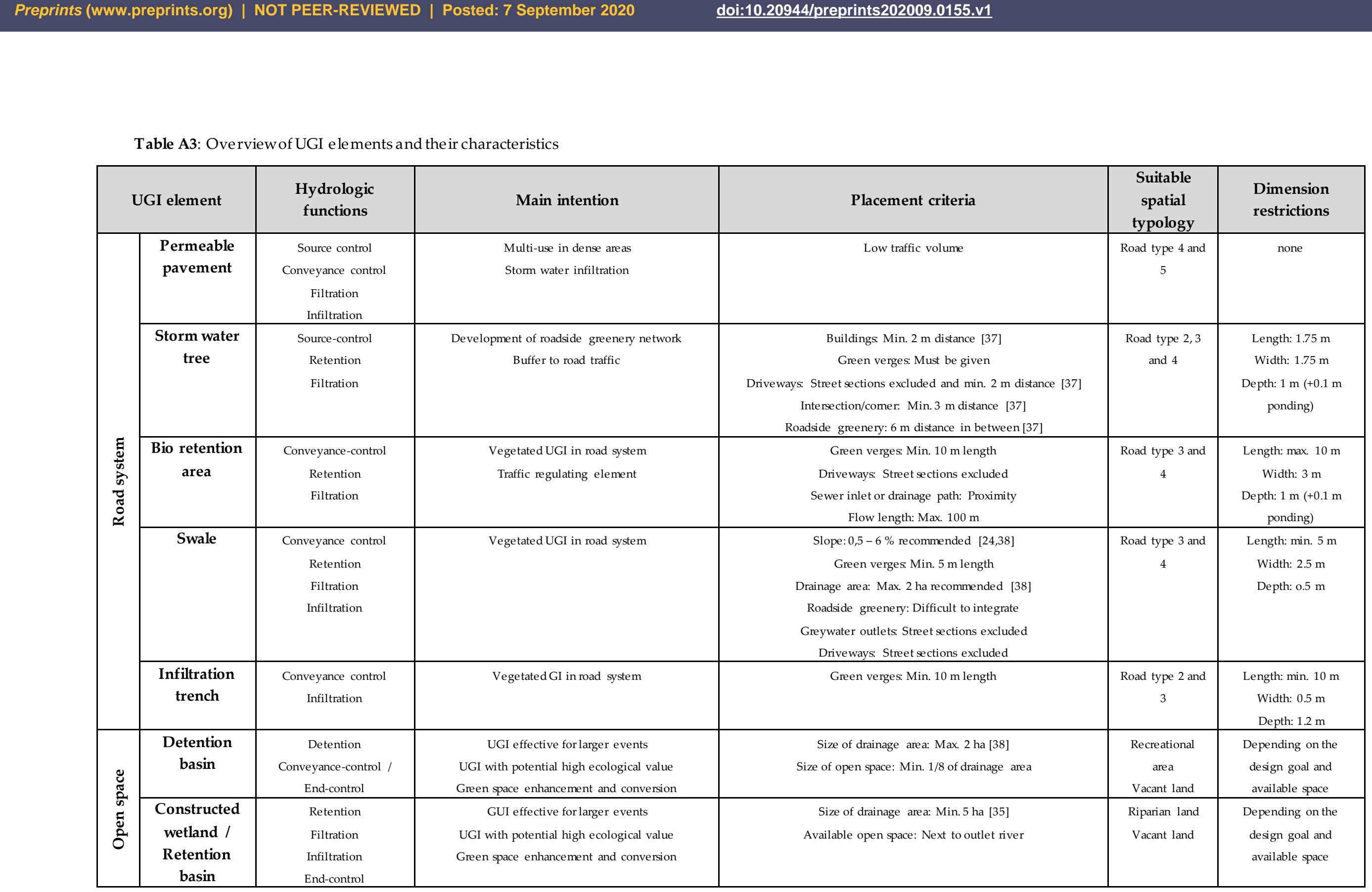




\section{References}

1. European Commission Towards an EU Research and Innovation policy agenda for nature-based solutions and renaturing cities. Final Report of the Horizon 2020 expert group on nature-based solutions and re-naturing cities; Brussels, Belgium, 2015;

2. NATURVATION Naturvation - Cities-Nature-Innovation Available online: https://naturvation.eu/about (accessed on Apr 23, 2020).

3. EPA What is green infrastructure? Available online: https://www.epa.gov/green-infrastructure/whatgreen-infrastructure (accessed on Apr 23, 2020).

4. $\quad$ BMT WBM Pty Ltd Evaluating Options for Water Sensitive Urban Design; Canberra, Australia, 2009;

5. WWAP/UN-WATER The United Nations World Water Development Report 2017: Wastewater: The Untapped Resource; Paris, 2018;

6. Díazo, S.; Settele, J.; Brondízio, E.; Ngo, H. T.; Guèze, M.; Agard, J.; Arneth, A.; Balvanera, P.; Brauman, K.; Butchart, S.; Chan, K.; Garibaldi, L.; Ichii, K.; Liu, J.; Subramanian, S. M.; Midgley, G.; Milosla vich, P.; Molnár, Z.; Obura, D.; Pfaff, A.; Polasky, S.; Purvis, A.; Razzaque, J.; Reyers, B.; Chowdhury, R. R.; Shin, Y.-J.; Visseren-Hamakers, I.; Willis, K.; Zayas, C. Summary for policymakers of the global assessment report on biodiversity and ecosystem services; Paris, France, 2019;

7. WWAP/UN-WATER The United Nations World Water Development Report 2018 Report: Nature-based solutions forwater; Paris, 2018;

8. Meerow, S. The politics of multifunctional green infrastructure planning in New York City. Cities 2020, 100, 102621, doi:10.1016/j.cities.2020.102621.

9. Hansen, R.; Olafsson, A. S.; van der Jagt, A. P. N.; Rall, E.; Pauleit, S. Planning multifunctional green infrastructure for compact cities: What is the state of practice? Ecol. Indic. 2019, 96, 99-110, doi:10.1016/j.e colind.2017.09.042.

10. Davies, C.; Hansen, R.; Rall, E.; Pauleit, S.; Lafortezza, R.; De Bellis, Y.; Santos, A.; Tosics, I. Green Infrastructure Planning and Implementation; 2015;

11. Golden, H. E.; Hoghooghi, N. Green infra structure and its catchment-scale effects: an emerging science. Wiley Interdiscip. Rev. Water 2018, 5, e1254, doi:10.1002/wat2.1254.

12. Singh, A.; Sarma, A. K.; Hack, J. Cost-Effective Optimization of Nature-Based Solutions for Reducing Urban Floods Considering Limited Space Availability. Environ. Process. 2020, doi:10.1007/s40710-01900420-8.

13. Ahern, J. Green infrastructure for cities: The spatialdimension. In Cities of the Future: Towards Integrated Sustainable Waterand Landscape Management; Novotny, V., Brown, P., Eds.; IW A Publishing, 2007 ISBN 9781843391364.

14. WHO Regional Office for Europe Urban green spaces and health-A Review of Evidence; Copenhagen, Denmark, 2016;

15. European Communities Towards a Local Sustainability Profile. European Common Indicators. Methodology Sheets.; Luxe mbourg, 2001;

16. Singh, A.; Sarma, A. K.; Hack, J. Cost-Effective Optimization of Nature-Based Solutions for Reducing Urban Floods Considering Limited Space Availability. Environ. Process. 2020, doi:10.1007/s40710-01900420-8.

17. Liu, W.; Chen, W.; Peng, C. Assessing the effectiveness of green infrastructures on urban flooding reduction: A community scale study. Ecol. Modell. 2014, 291, 6-14, doi:10.1016/j.e colmodel.2014.07.012.

18. Lähde, E.; Khadka, A.; Tahvonen, O.; Kokkonen, T. Can We Really Have It All? -Designing 
Multifunctionality with Sustainable Urban Drainage System Elements. Sustainability 2019, 11, 1854, doi:10.3390/su11071854.

19. Hack, J.; Molewijk, D.; Beißler, M. R. A Conceptual Approach to Modeling the Geospatial I mpact of Typical Urban Threats on the Habitat Quality of River Corridors. Remote Sens. 2020, 12, 1345, doi:10.3390/rs12081345.

20. Beißler, M. R.; Hack, J. A Combined Field and Remote-Sensing based Methodology to Assess the Ecosystem Service Potential of Urban Rivers in Developing Countries. Remote Sens. 2019, 11, 1697, doi:10.3390/rs11141697.

21. Zepp, H.; Groß, L.; Inostroza, L. And the winner is? Comparing urban green space provision and accessibility in eight European metropolitan a reas using a spa tia lly explicit a pproach. Urban For. Urban Green. 2020, 49, 126603, doi:10.1016/j.ufug.2020.126603.

22. Naumann, S.; Rayment, M.; Nolan, P.; Forest, T. M.; Gill, S.; Infrastructure, G.; Forest, M. Design, implementationand cost elements of Green Infrastruct ure projects; Berlin, 2011;

23. Bartesaghi Koc, C.; Osmond, P.; Peters, A. Towards a comprehensive green infrastructure typology: a systematic review of approaches, methods and typologies. Urban Ecosyst. 2017, 20, 15-35, doi:10.1007/s11252-016-0578-5.

24. Beven, K. The SuDS Manual; 2015; ISBN 9780860177609.

25. Kellagher, R.; Laughlan, C. Use of SUDS in High Density Developments; London, UK, 2005;

26. Credit Valley Conservation; Toronto Region Conservation Authority Low Impact Development Stormwater Management Planning and Design Guide. Version 1.0; Toronto, Canada, 2010;

27. PUB Engineering Procedures for ABC Waters Design Features; Singapoore, 2014;

28. PUB Managing Urban Runoff - Drainage Handbook; Singapore, 2013;

29. Victoria State Government Water Sensitive Urban Design Guidelines; Melbourne, Australia, 2013;

30. EPA Preliminary data summary of urban storm water best management practices; Washington D.C., USA, 1999;

31. JTF Minimum Design Criteria for Implementation of certain Best Management Practices for Storm Water Runoff Treatment Options; USA, 2001;

32. U.S. Army Corps of Engineers Army Low Impact Development Technical User Guide; 2013;

33. Woods Ballard, B.; Kellagher, R.; Martin, P.; Jefferies, C.; Bray, R.; Shaffer, P. The SuDS Manual; London, UK, 2015;

34. Woods Ballard, B.; Kellagher, R.; Martin, P.; Jefferies, C.; Bray, R.; Shaffer, P. The SuDS manual \& Site handbook for the construction of SuDS; London, UK, 2007;

35. Ministry of the Environment Stormwater Management Planning and Design Manual; Onta rio, canada, 2003;

36. UNa Lab Nature Based Solutions - Technical Handbook, Part II; Brussels, Belgium, 2019;

37. Municipalidad de Curridabat Protocolo para Aceras Dulces; Curridabat, Costa Rica, 2019;

38. Credit Valley Conservation; Toronto Region Conservation Authority Low Impact Development Stormwater Management Planning and Design Guide. Version 1.0. Toronto and Region Conservation Authority and Cre dit Valley Conservation Authority. 2010, 4-92-4-94.

39. Romnée, A. Comparis on between literature guidelines and developed projects regarding the land use criteria for the selection of the best management practices for stormwater. In Water Resources Management VIII; 2015; Vol. 1, pp. 195-208.

40. Kellagher, R.; Martin, P.;Jefferies, C.; Bray, R.; Shaffer, P.; Wallingford, H. R.; Woods-Ballard, B.; W oods Ballard, B.; Construction Industry Research and Information Association; Gre at Britain; De partment of Trade and Industry; Environment Agency The SUDS manual; 2015; ISBN 9780860176978.

41. Fryd, O.; Dam, T.; Jensen, M. B. A planning framework for sustainable urban drainage systems. Water 
Policy 2012, 14, 865-886, doi:10.2166/wp.2012.025.

42. Kim, J. Exploring green infrastructure benefits at house and neighborhood scale: case study of Illinois, USA. Landsc. Ecol. Eng. 2018, 14, 165-174, doi:10.1007/s11355-017-0331-0.

43. Mentens, J.; Raes, D.; Hermy, M. Green roofs as a tool for solving the rainwater runoff problem in the urbanized 21st century? Landsc. Urban Plan. 2006, 77, 217-226, doi:10.1016/j.landurbplan.2005.02.010.

44. Rossman, L. A.; Huber, W. C. Storm WaterManagement Model Reference Manual, Volume I - Hydrology; U.S. Environmental Protection Agency, Office of Research and Development, Water Supply and Water Resource Division: Cincinnati, Ohio, 2016; Vol. I;

45. Palla, A.; Gnecco, I. Hydrologic modeling of Low Impact Development systems at the urban ca tchment scale. J. Hydrol. 2015, 528, 361-368, doi:10.1016/j.jhydrol.2015.06.050.

46. Kong, F.; Ban, Y.; Yin, H.; James, P.; Dronova, I. Modeling stormwater management at the city district level in response to changes in land use and low impact development. Environ. Model. Softw. 2017, 95, 132-142, doi:10.1016/j.envsoft.2017.06.021.

47. Schwarz, N.; Moretti, M.; Bugalho, M. N.; Davies, Z. G.; Haase, D.; Hack, J.; Hof, A.; Melero, Y.; Pett, T. J.; Knapp, S. Understanding biodiversity-ecosystem service relationships in urban areas: A comprehensive literature review. Ecosyst. Serv. 2017, 27, 161-171, doi:10.1016/j.ecoser.2017.08.014.

48. Woods Ballard, B.; Wilson, S.; Udale-Clarke, H.; Illman, S.; Scott, T.; Ashley, R.; Kellagher, R. The SuDS Manual; London, UK, 2015;

49. Monberg, R. J.; Howe, A. G.; Ravn, H. P.; Jensen, M. B. Exploring structural habitat heterogeneity in sustainable urban drainage systems (SUDS) for urban biodiversity support. Urban Ecosyst. 2018, 21, 1159-1170, doi:10.1007/s11252-018-0790-6.

50. Norton, B. A.; Coutts, A. M.; Livesley, S. J.;Harris, R. J.; Hunter, A. M.; Williams, N. S. G. Planning for cooler cities: A framework to prioritise green infrastructure to mitigate high temperatures in urban landscapes. Landsc. Urban Plan. 2015, 134, 127-138, doi:10.1016/j.landurbplan.2014.10.018.

51. NACTO Urban Street Design Guide Available online: https://nacto.org/publication/urban-street-designguide/ (acce ssed on Jun 17, 2020).

52. Municipality of Curridabat Protocolopara Aceras Dulces; Curridabat, Costa Rica, 2019;

53. Kuller, M.; Bach, P. M.; Roberts, S.; Browne, D.; Deletic, A. A planning-support tool for spa tial suitability assessment of green urban stormwater infrastructure. Sci. Total Environ. 2019, 686, 856-868, doi:10.1016/j.scitotenv.2019.06.051.

54. Giacomoni, M. H.; Joseph, J. Multi-objective evolutiona ry optimization and Monte Carlo simula tion for placement of low impact development in the catchment scale. J. Water Resour. Plan. Manag. 2017, 143, 115, doi:10.1061/(ASCE)WR.1943-5452.0000812.

55. Hasala, D.; Supak, S.; Rivers, L. Green infrastructure site selection in the Walnut Creek wetland community: A case study from southeast Raleigh, North Carolina. Landsc. Urban Plan. 2020, 196, 103743, doi:10.1016/j.landurbplan.2020.103743.

56. Tran, T. J.; Helmus, M. R.; Behm, J. E. Green infrastructure space and traits (GIST) model: Integrating green infrastructure spatial placement and plant traits to maximize multifunctionality. Urban For. Urban Green. 2020, 49, 126635, doi:10.1016/j.ufug.2020.126635. 